Electronic portfolios in early childhood education:

Parent-teacher communication

By

Amanda Higgins

\begin{abstract}
A three paper thesis
Submitted to the Victoria University of Wellington

in partial fulfillment of the requirements for the degree of

Masters of Education
\end{abstract}

Victoria University of Wellington

2015 


\begin{abstract}
Electronic portfolios (ePortfolios) are a new phenomenon in early childhood education (ECE) and there is minimal existing research available on their use and effectiveness as a learning and communication tool in ECE.

This thesis presents an exploratory case study of an ECE centre, positioned within a constructive-interpretivist paradigm, which investigated communication between teachers and families via ePortfolios. Data used in the study were drawn from online surveys, document analysis of ePortfolios, individual interviews, and focus group interviews with parents and teachers. Thematic analysis identified three main themes; the benefits and drawbacks of communicating via the ePortfolio, the online tools that supported or constrained communication, and the types of communication that were evident.

Several implications for teachers' practice arise from this study. First, the ePortfolio enabled communication to easily flow between settings, and provided another avenue for teachers and parents to communicate. Second, the different levels of communication parents and teachers engaged in via the ePortfolio had potential to influence their on-going communication, relationships, and children's learning. To extend on-going learning and positive learning outcomes for children, online communication could be scaffolded so that a focus on relationships moves toward to a greater focus on children's learning. Finally, levels of trust between teachers and parents were apparent, though more complex elements of trust such as competence and openness were less evident. Teachers could consider ways to develop these with parents to further enhance trust and communication.
\end{abstract}




\section{Acknowledgements}

I would firstly like to acknowledge the case study centre and all participants who voluntarily took part in the study. I wish to thank them for their time and willingness to discuss and share their experiences.

Secondly I would like to thank my supervisor, Dr. Sue Cherrington for her unwavering support, critical feedback, and total belief that I would complete my thesis. I am really going to miss our regular meetings. I would also like to thank Victoria University for the financial support via the research grant scheme.

And finally thank-you to my family, friends, and work colleagues who have endured this thesis with me, and put up with my lack of attention and time to be with them. 


\section{CONTENTS}

Abstract ii

Acknowledgements iii

List of tables vii

List of figures vii

List of appendices viii

CHAPTER 1: INTRODUCTION 1

1.1 Background of the study 2

1.1.1 Information about the ePortfolio platform 2

$\begin{array}{ll}\text { 1.2 The research questions } & 3\end{array}$

1.3 Organisation of the thesis 4

CHAPTER 2: LITERATURE REVIEW 5

2.1 Ecological theory $\quad 5$

2.1.1. Balance of power 6

$\begin{array}{lr}\text { 2.1.2. Trust } & 10\end{array}$

2.1.3. Goal consensus 13

2.2. Communication literature in relation to ECE 14

$\begin{array}{ll}2.2 .1 \text {. One-way communication } & 16\end{array}$

$\begin{array}{ll}\text { 2.2.2. Two-way communication } & 17\end{array}$

$\begin{array}{ll}2.2 .3 \text {. Barriers to two-way communication } & 18\end{array}$

$\begin{array}{lr}\text { 2.2.4. Communicating assessment information } & 19\end{array}$

2.3 Communication via ICT in ECE 20

2.4 Teacher-parent communication via ePortfolios 22

CHAPTER 3: METHODOLOGY 26

3.1 Rationale for research paradigm and methodology 26

$\begin{array}{ll}3.1 .1 \text { Case study } & 27\end{array}$

3.2 Participants 28

3.3 Data sources for this study 29

$\begin{array}{lr}\text { 3.3.1 Document analysis } & 30\end{array}$

3.3.2. Online surveys to all teachers and families 33

3.3.3 Semi-structured individual interviews 34

3.3.4 Observer as participant observations $\quad 35$

3.3.5 Focus group interviews 36

3.4 Ethical considerations $\quad 36$

3.5 Trust worthiness and reliability 37

$\begin{array}{ll}3.5 .1 \text { Descriptive validity } & 38\end{array}$

$\begin{array}{ll}3.5 .2 \text { Interpretive validity } & 38 \\ 3.5 .3 \text { Refexivity } & 38\end{array}$

$\begin{array}{ll}3.5 .3 \text { Reflexivity } & 38\end{array}$

3.5.4. Triangulation 39 
3.6 Data analysis $\quad 39$

3.6.1 Qualitative data analysis $\quad 39$

3.6.1.1 Thematic analysis $\quad 39$

$\begin{array}{ll}\text { 3.6.2 Quantitative analysis } & 41\end{array}$

3.7 Conclusion 41

CHAPTER 4: RESULTS 42

4.1 Benefits and drawbacks of communication via ePortfolios 42

4.1.1 Being informed 42

4.1.2 Connecting face-to-face conversations 44

4.1.2.1 Teachers and parents $\quad 45$

4.1.2.2 Teachers and teachers $\quad 46$

4.1.2.3 Families and children $\quad 47$

$\begin{array}{ll}\text { 4.1.3 Building relationships } & 47\end{array}$

4.1.4 Supporting children's learning $\quad 49$

4.1.4.1. Online dialogue that supported learning 51

4.1.5 Drawbacks of communicating through the ePortfolio 54

4.2 Enablers and barriers of the ePortfolio platform 55

4.2.1 Ease of use

4.2.2 Barriers created by the ePortfolio tools in regards to communication 57

4.4 Content of communication evident through online comments 57

$\begin{array}{ll}\text { 4.4.1 Affirmation } & 60\end{array}$

4.4.2 Giving further information $\quad 61$

4.3.3 Appreciation $\quad 63$

4.4.4 Links to potential follow up $\quad 65$

4.4.5 Conversational $\quad 65$

4.4.6 Asking a question 66

4.5 Framework of effective two-way communication used in this study $\quad 66$

4.5.1 Trust 66

4.5.2 Balance of power $\quad 69$

4.5.3 Goal consensus 71

4.6 Summary 73

CHAPTER 5: DISCUSSION

5.1 How ePortfolios facilitate communication between families and teachers

5.1.1. One-way communication 75

5.1.2 Two-way communication $\quad 75$

5.1.3 ePortfolio tools that facilitate communication 76

5.2. Types of communication fostered 76

5.2.1 Content of communication 76

5.2.2 Surface versus substantive dialogue 77

5.3 Impact of communication on relationships and on-going learning 
5.7 Contribution to research

5.8 Limitations

81

5.9 Further research

83

5.10 Concluding implications and issues arising from this study 


\section{List of tables}

Table 2.1: Communication styles of different family oriented ECE settings 8

Table 3.1: Number of learning stories commented on by participants 31

Table 3.2: Numbers of stories and comments by teachers and parents 32

Table 3.3: Time child had ePortfolio or teacher had been using it 34

Table 4.1: Extent ePortfolios helped parents and wider whānau understand their child's learning at the centre

Table 4.2: Extent ePortfolios strengthened communication between home and centre

Table 4.3: Extent ePortfolios strengthened parent-teacher relationships 48

Table 4.4: Extent ePortfolios supported different types of communication 53

Table 4.5: Categories coded from the example online comment 58

Table 4.6: Types of comments made by teachers, parents, and wider whānau $\quad 59$

Table 4.7: Examples of different types of affirming comments. 60

Table 4.8: Examples and frequency of types of information shared 62

Table 4.9: Measures of parents' and teachers' trust in each other 67

Table 4.10: Parents aspirations for their children shared with teachers 71

\section{List of figures}

$\begin{array}{ll}\text { Figure 3.1: Process of data collection } & 30\end{array}$

Figure 4.1: Types of comments made by participants 59 


\section{List of appendices}

Appendix 1: Teachers' online survey 93

Appendix 2: Information and consent for survey 96

Appendix 3: Teachers' information sheet 99

$\begin{array}{ll}\text { Appendix 4: Teachers' and parents' consent forms } & 104\end{array}$

$\begin{array}{ll}\text { Appendix 5: Interview protocol } & 108\end{array}$

Appendix 6: Transcriber confidentiality agreement 112

$\begin{array}{ll}\text { Appendix 7: Centre permission form } & 113\end{array}$

Appendix 8: Second level of information and consent for interview and focus group $\begin{array}{ll}\text { participants } & 118\end{array}$

$\begin{array}{ll}\text { Appendix 9: Research assistant confidentiality agreement } & 123\end{array}$

$\begin{array}{ll}\text { Appendix 10: Table outlining different codes for data sources } & 124\end{array}$

$\begin{array}{ll}\text { Appendix 11: Theme descriptions of parent survey } & 125\end{array}$ 


\section{CHAPTER 1: INTRODUCTION}

This thesis examines the influence of ePortfolios on parent-teacher communication in one early childhood (EC) centre. Research and scholarship place great importance on parent-teacher communication to make a positive difference for children (Hughes \& MacNaughton, 2001; Stonehouse \& Gonzalez Mena, 2004; Whalley, 2007; Meade, 2012). In New Zealand (NZ), families are recognised as being central to children's learning in the EC curriculum, Te Wharriki (Ministry of Education (MoE, 1996). One of the four principles is Family and Community, which states:

Families should be part of the assessment and evaluation of the curriculum as well as children's learning and development...Observations and records should be part of two-way communication that strengthens the partnership between early childhood settings and families (MoE, 1996, p.30)

The importance of communication between teachers and families is also reflected in the NZ Government's regulated curriculum standards for EC services:

Positive steps are taken to respect and acknowledge the aspirations held by parents and whānau for their children.

Regular opportunities (formal and informal) are provided for parents to communicate with adults providing education and care about their child, and share specific evidence of the child's learning (MoE, 2008, p. 9).

One way that ECE services communicate with parents, especially about children's learning, is through portfolios, which are commonplace in NZ ECE settings (Education Review Office (ERO), 2008). A portfolio can be described as a purposeful collection of artifacts that tells the story of a child's effort, progress and/or achievement (Abrami \& Barrett, 2005). While most services have been using hardcopy portfolios for the last two decades, ePortfolios are a newer development. Eportfolios can offer unique advantages over hard-copy portfolios, as they are able to integrate multimedia tools to organise learning, more effectively illustrating the progress of learning over time. They are also easily shared and contributed to, with feedback held in one place (Abrami \& Barrett, 2005). Since 2009 several commercial 
ePortfolio platforms designed for ECE services have been created. They offer an internet platform for multiple children's portfolios to be easily linked and accessible to teachers, parents, and families.

I first became interested in ePortfolios when I started my postgraduate study, completing a paper on information and communication technology (ICT) in education. I then became a regional facilitator for a MoE funded pilot professional learning project exploring the potential of ICT in ECE (described later in section 2.3). As part of this project I worked with ECE services implementing, for example, blogs and digital storytelling using digital cameras and other ICT tools. The biggest barrier to engagement seemed to be the lack of a mechanism that allowed easy, accessible, and secure sharing of children's learning between teachers, families, and children.

I later trialled creating and using a blog in the centre I was teaching in. I found this created extra workload for teachers, parents didn't access it as much as I had hoped, and few parents made use of its commenting tools. The centre was then offered the opportunity to take part in a pilot project trialing a new ePortfolio platform. The immediate difference I could see was in parents' engagement with the ePortfolio compared with hard-copy portfolios and the blog, as well as teachers' excitement at receiving regular feedback from parents. With my interest in ePortfolios ignited, I decided to undertake research to explore what made this difference to parents' and teachers' engagement with the ePortfolio, with a particular focus on the communication it fostered.

\subsection{Background of the study}

The study was carried out in a community-based not-for-profit ECE centre (referred to as 'the centre' in the thesis). This centre was chosen because of their relative longterm use of ePortfolios. I also had a previous relationship with the centre, so had an understanding of their culture and practice.

\subsubsection{Information about the ePortfolio platform}

Particular to the ePortfolio platform that the centre was using, parents were administrators of their child's ePortfolio and controlled who could be invited to see it (other than the teachers at the centre). Once they left the centre, parents could 
disconnect their child's ePortfolio from the centre and still keep and add content for as long as they chose.

Before teachers set up a child's ePortfolio, parents signed a consent form. This included the purpose of the ePortfolio and expectations that content were positive, and any inappropriate content would be removed.

The child's individual ePortfolio was where teachers, the child's parents, and invited wider whānau could post stories and comments. There was also a 'tagging' function where the storywriter could add 'tags' that related to the relevant learning. Teachers could write stories to one child, several children, or to all the children in the centre community. If a story was written to more than one child, every person invited to each child's ePortfolio included in the story would see comments from each contributor. Parents and wider whānau could only add stories to their own child's ePortfolio. Every time a story was added about a child, everyone invited to the child's ePortfolio received an email notification, unless they had chosen to deactivate this function. Other tools available on the ePortfolio had less relevance to this study so have not been discussed here.

\subsection{The research questions}

The study aimed to investigate the types of communication afforded by the ePortfolio, and how these might influence relationships between teachers and parents, as well as children's learning.

The following research questions were developed:

1. How do ePortfolios facilitate communication between families and teachers in an EC centre?

2. What type of communication is fostered through the use of ePortfolios in an EC centre?

3. What impact does communication through the use of ePortfolios have on teacher-parent relationships and children's on-going learning?

4. How do teachers' values and beliefs about communicating with families influence communication through ePortfolios in an EC centre? 


\subsection{Organisation of the thesis}

This introductory chapter has explained what an ePortfolio is, introduced the development of the research interest in this topic, and briefly described how communication between parents and teachers is mandated in ECE services in NZ.

Chapter two presents the literature review undertaken for the research, organised into two main themes. The first reviews literature in relation to a communication framework drawn from key concepts within Bronfenbrenner's ecological theory focusing on research pertaining to enhanced trust, shared power, and goal consensus between parents and teachers. The second section reviews ECE literature and research on parent-teacher communication, assessment, ICT, and ePortfolios.

Chapter three describes and explains the methodology used in this research, conducted within an interpretive paradigm. Within this paradigm, a mixed method approach is taken, using case study methodology. Ethical processes and protocols establishing validity are also discussed.

Chapter four presents the findings arising from this research. Three main themes established through inductive analysis of the qualitative data are presented and described supported by analysis of quantitative data. Deductive analysis is used to investigate the three concepts highlighted by Bronfenbrenner (1979) and these results are explained.

Chapter five discusses the key findings in relation to the research questions. The three key concepts based on Bronfenbrenner's hypothesis are discussed in relation to the research findings and literature. The contributions this research has made, limitations of the research, and considerations for future research are then described. Lastly implications and issues arising from this research are discussed. 


\section{CHAPTER 2: LITERATURE REVIEW}

This review of literature focuses on four areas of scholarship to inform the investigation of communication through ePortfolios. The first section focuses on Ecological theory (Bronfenbrenner, 1979) and how this provides a useful framework for theorising about effective two-way communication. The second section focuses on scholarship about communication between teachers and families in ECE settings, whilst the third section focuses more closely on ICT scholarship in NZ ECE, especially in regards to communication. The last section reviews ePortfolio research with a focus on communication between teachers and parents in ECE.

\subsection{Ecological theory}

Ecological theory (Bronfenbrenner, 1979) is based on the premise that a person's development is influenced by the environmental systems that they interact with. Bronfenbrenner describes these five systems starting with the microsystem, which is the immediate environment in which the child spends time, such as the home. The second system - the mesosystem is described as "a set of interrelations between two or more settings in which the developing person becomes an active participant" ( $p$. 209), for example, the home and the ECE setting. The exosystem involves links between a setting that a person does not have direct involvement in, and their immediate setting, such as a child's mother's workplace. The macrosystem is the culture in which a person lives; it includes customs, laws, and cultural values. The chronosystem encompasses the dimension of time and the major life transitions of the person. This study focuses on the first two systems; the micro and mesosystems, whilst acknowledging the indirect influence of the other three systems.

The mesosystem is the connections between the person's microsystems, - in this study the case study centre and the child's home. There are four general types of interconnections espoused within this system - multi-setting participation, indirect linkage, intersetting communication, and intersetting knowledge. Multi-setting participation is required to have a mesosystem; this is when a person actively participates in more than one setting, such as a child attending an ECE centre alongside their family setting. Indirect linkage refers to a third party who links people from one setting that the child is involved in with the other setting, for example a mother goes with the child to the ECE setting. Intersetting communication 
includes the messages transmitted from one microsystem to another with the purpose of providing information to people in the other setting. This can be done in multiple ways and can be one-or two-way, for example, newsletters or phone conversations. Intersetting knowledge refers to experience or information that exists in one setting about the other setting. Often this is achieved through intersetting communication. An ePortfolio can be considered a mesosystem tool that connects the microsystems of the child's home and early childhood setting, supporting intersetting communication and intersetting knowledge.

Bronfenbrenner (1979) hypothesised that young children's “developmental potential of participation in multiple settings will vary directly with the ease and extent of twoway communication between those settings" (p. 216). He saw families' inclusion being a key part of the communication network, and proposed that interchange between settings was enhanced through processes that:

are bidirectional, sustain and enhance mutual trust and goal consensus, and exhibit a balance of power favorable to those linking parties who facilitate action in behalf of the developing person (p.218).

Devito (1995) defined communication as the act, by one of more persons of sending and receiving messages that are distorted by noise, occur within a context, have some effect, and provide some opportunity for feedback. Loveridge (2002) extended on this, explaining communication is not just oral or expressing one's viewpoint, but a reciprocal interaction between others and ourselves recognising how we both affect and are affected by the communication. This definition highlights the reciprocal nature of effective communication.

Bronfenbrenner's concept of interchanges between settings enables communication. I have applied the conditions espoused by Bronfenbrenner: a balance of power, enhanced mutual trust, and goal consensus, as a framework to investigate communication between parents and teachers. These are discussed below using literature and research from education, early intervention, and social work.

\subsubsection{Balance of power}

Bronfenbrenner (1979) described two ways that balance of power was applied in his hypothesis. The first was one person in the dyad (i.e., the parent) having more 
influence over the other (i.e. the child), and that it was important for the child to learn about these power differentials in relationships, as they happened throughout life. The other way of conceptualising balance of power was more dynamic, with a gradual shift towards the developing person, giving them more control over their situation. It is in this continuing shift where optimal development and learning happens.

This study draws upon the second dynamic concept of balance of power. In the above quote Bronfenbrenner describes linking parties having the balance of power. In the ECE context I suggest parents as the linking parties, as they generally spend time with the child in both microsystems of home and the centre, and therefore should have the most influence on behalf of their child.

Within teacher-parent relationships, power determines whose knowledge or expertise is privileged. Several models are useful in examining power relationships between teachers and families. Dunst, Johanson, Trivette, and Hamby's (1991) model was developed to measure the degree to which family-orientated intervention policies and practices in the USA were family centred. They synthesized seven pieces of legislation and compared these to responses at both state and practitioner level in education, health and human services, in regards to their family friendliness. Dunst et al. (1991) found four broad types of family-orientated early intervention programmes existed: professional centred, family allied, family focused, and family centred. These present a continuum of power or control from the professional in the professional centred programme, to the parent in the family centred programme. Programmes differed in the assumptions of roles and responsibilities of both the professional and parents, and these assumptions affected the practices used by professionals to support families. Family centred practices were associated with a greater sense of personal control and heightened feelings of well-being for the consumer, compared with the professionally centred services (Trivette, Dunst, \& Hamby, 1996).

In a review of qualitative and quantitative research of family-centred practices in early intervention, early childhood, primary, and secondary school settings Dunst (2002) found that family centred practice had two elements - relational and participatory behaviour. Relational behaviour included teachers' beliefs and attitudes towards families, and practices such as demonstrating respect and active listening. Participatory behaviour included strategies for building confidence and competence in 
families, such as providing complete and unbiased information so that families could make informed decisions. The further services moved along the continuum towards a parent driven paradigm the more both these types of practices were used by teachers.

Osher and Osher (2002) provided a similar framework from research completed with service delivery systems for children with emotional disturbance. They described a paradigm shift moving from provider driven to family driven characteristics. For example, in the family driven paradigm parents were collaborators in decision making for their child and assessment was strength based. Osher and Osher (2002) advocated that to be responsive to a child with emotional disturbance, the children and families culture, language, spiritual beliefs, social values, and ethnicity all needed to considered and respected.

ECE literature regarding power relationships indicates the difference between parent involvement and parent partnership resides in how power is shared between the two parties (Stonehouse \& Gonzalez-Mena, 2004). Porter (2008) combined Osher and Osher's (2002), and Dunst et al.'s (1991) frameworks to develop one appropriate for ECE services that included a communication style reflective of each category (see table 2.1):

Table 2.1: Communication styles of different family oriented ECE settings

\begin{tabular}{|c|c|c|c|c|}
\hline & $\begin{array}{c}\text { Professional- } \\
\text { driven }\end{array}$ & $\begin{array}{c}\text { Family } \\
\text { orientated }\end{array}$ & Family centred & Family-driven \\
\hline $\begin{array}{c}\text { Communication } \\
\text { style }\end{array}$ & $\begin{array}{l}\text { One-way flow } \\
\text { of information }\end{array}$ & $\begin{array}{l}\text { Communication is } \\
\text { task and parent } \\
\text { education focused }\end{array}$ & $\begin{array}{l}\text { Communication } \\
\text { aims to build a } \\
\text { relationship and } \\
\text { empower parent } \\
\text { participation }\end{array}$ & $\begin{array}{l}\text { Communication } \\
\text { aims to build a } \\
\text { relationship and } \\
\text { support parents' } \\
\text { interest in their } \\
\text { child's education } \\
\text { Communication is } \\
\text { responsive to } \\
\text { parents, and } \\
\text { collaborative } \\
\text { consultation is } \\
\text { evident }\end{array}$ \\
\hline
\end{tabular}


When teachers are in control in the parent-teacher relationship terms like parent involvement and parent help are used. When parents are in control parents are more likely to be considered as clients. When there is more of a balance of power in the relationship, terms such as reciprocal engagement, shared decision-making, and participation are used (Hedges, 2010) and there are better outcomes for all involved (Stonehouse \& Gonzalez-Mena, 2004).

Hughes and MacNaughton (1999) reviewed 162 articles involving parent-teacher communication in ECE settings published in the 1990's. They found three main views were apparent - parent as teacher, parent as collaborator, and parent as decision maker. In each view the different expertise held by parents and teachers created a hierarchy, which privileged either staff or parent expertise or discredited or ignored it. Parents as teachers was evident in $56 \%$ of the reviewed literature. This view privileged teachers' knowledge, where staff taught parents how to teach and raise their children. Only 5\% of the literature positioned Parents as collaborators and 4\% positioned parents as decision makers. The other $36 \%$ of articles related to advocating for parent involvement or resolving communication issues.

Extending on what was reported by Hughes and MacNaughton (1999), an American collective case study found that teachers in one setting held different perspectives on power and status relations between them and parents (Wilgus, 2005, p.270). Wilgus investigated differences in beliefs between teachers and parents about the parents' role in infant and toddler ECE settings. Four different perspectives amongst teaching staff indicating different power models were evident; at one extreme teachers' status and power superseded that of parents with teachers instructing parents about how to raise their children, to the opposite end of the spectrum where teachers did not think it was appropriate to tell parents what was best for their children.

Over the last two decades ECE theory has moved from a developmental to a sociocultural paradigm (Souto-Manning \& Swick, 2006) and with this change, a multiplicity of knowledge is now valued. Rather than believing the teacher is the expert and excluding parents from partnership roles such as decision-making, shared power with multiple input is now espoused in ECE (Hedges, 2010). There is potential for this change to create conflict for teachers, especially if their values and beliefs still sit within a developmental paradigm. 
Whalley (2007) explains this further, pointing out that if teachers view parents more as helpers rather then active participants, parents' contributions take on a less powerful role. This was supported by Hughes and MacNaughton's (2001) study where some teachers believed that 'good' parent involvement meant parents respected their expert knowledge about children. Furthering this idea Hughes and MacNaughton (2011) described how teachers could 'other' parents by using professional technical language, which privileged the teacher's knowledge over the parent's knowledge.

\subsubsection{Trust}

Adams and Christenson (2000) define trust within parent-teacher relationships as:

Confidence that another person will act in a way to benefit or sustain the relationship, or the implicit or explicit goals of the relationship, to achieve positive outcomes for students (p. 480).

Such trust is built through frequent ongoing everyday responsive communication with parents, and is essential to having meaningful and authentic communication (Swick, 2003). It is an iterative process that is dependent on reciprocity such as sharing ideas, information, feelings, and resources. Trust is increased through parent-teacher interaction (Adams \& Christenson, 1998), however in a later study Adams and Christenson (2000) found the nature of the interaction was a better predictor of trust than frequency of interaction.

Research from across the educational, early intervention, and marital relationships fields investigating relational trust, provide some helpful frameworks that can be applied to ECE settings. A hierarchal framework of trust is provided by Rempel, Holmes, and Zanna (1985) who used it in a small quantitative study of 46 couples in relationships. The purpose of this study was to provide a theoretical model of interpersonal trust. The scale they created was used to measure levels of trust in close relationships: predictability (lowest level), dependability, and faith (highest level).

The measurement tool was adapted by Adams and Christenson (2000), making it more relevant to parent-teacher relationships. Their descriptive quantitative study investigated the differences in trust levels between 1234 parents and 209 teachers in a school district in the USA. They also measured parent trust levels in regards to 
ethnicity, socio-economic status, and parent involvement. Because teachers had less need to trust the parent, their trust levels were often not as high as the parents. If parents and teachers did not have opportunities for regular dialogue to build trust, they were most likely to stay at the lowest level of trust, predictability where parents and teachers continually searched and tested out each other's trustworthy behaviours.

Another model is provided by Goddard, Tschannen-Moran, and Hoy (2001) who identified five key elements of trust: benevolence, reliability, competence, honesty, and openness. Benevolence was described as showing caring and friendliness; reliability referred to predictability of expectations; competence was where each party is expected to be competent in their primary role; honesty referred to truthfulness, integrity and consistency; openness was the extent to which relevant information was shared, openness and trust were reciprocal, so when people trusted each other they were likely to be more open, and when people were more open and shared information a more trusting relationship occurred. Goddard et al.'s (2001) quantitative study investigated trust as an essential part of relationships that facilitated student success in urban primary schools from the teachers' perspective. Teachers' trust of students and parents was a significant predictor of variance in student achievement. Findings also indicated that teachers in schools with poorer families seemed to find it harder to build trust.

These five elements of trust have been used in other studies as a method of measuring trust. For example, Janssen, Bakker, Bosman, and Leseman (2012) used them in a small quantitative study to investigate the trust relationship between teachers and parents in a Dutch primary school. In particular they wanted to know if trust was related to ethnicity and reading level. Drawing on the earlier work of Adams and Christenson (2000), Goddard et al. (2001), and Rempel et al. (1985) they created two new instruments - one for parents and one for teachers - that measured the five facets of trust. Janssen et al. (2012) found the five facets of trust were bi-directional: for example in regards to competence, the parent trusted that the teacher was a competent teacher, and the teacher trusted that the parent was a competent parent, as in Adams and Christenson's (2000) study. The reciprocal nature of these facets did not mean that equal levels of trust were found between parents and teachers: parents were found to have more trust in teachers regarding reliability, honesty, and competence than 
teachers had in parents. The findings also indicated that while ethnicity had no influence on parents trust in teachers, teachers had lower levels on all five trust facets for immigrant families compared with Native Dutch families. This study also supported Goddard et al.'s (2001) findings where teachers' trust levels affected students' achievement levels. Janssen et al. (2012) found teachers trust levels had a role in the child's reading performance, especially in regards to the elements of benevolence and openness. This study was conducted in one primary school so generalisability is limited.

Beyond the parent-teacher partnership literature, the Best Evidence Synthesis (BES) on school leadership identified a similar model to Goddard et al. (2001). Robinson, Hohepa, and Lloyd (2009) listed four determinants of relational trust: interpersonal respect, personal regard for others, competence in role, and personal integrity. Interpersonal respect recognised the importance of each person's role, and how each depended on the other. Personal regard involved caring about others, in both a professional and personal capacity. Competence in role involved trusting that those in a position of responsibility dealt with incompetence and supported school improvement, and lastly personal integrity was the consistency between what words teachers said and what teachers did, and the values and ethical principles that underlaid the decisions made, in the best interests of children.

Research investigating trust in online communities offered another lens to view trust. Booth's (2011) multiple case study of professional learning communities found that fostering and sustaining knowledge sharing was the most difficult challenge, and a key factor for knowledge sharing in online communities was trust. Three elements that supported the establishment of a trusting environment were: guidelines for participation and netiquette; the credibility of the moderator; and the competence of members.

ECE literature regarding trust recognised there was no simple formula to build trust (Souto-Manning \& Swick, 2006). Communication involving respect and sensitivity built trust, ultimately resulting in more intimate knowledge being shared about children, and therefore a better understanding of how best to support children's learning (Porter, 2008). It also took time for parents to build trust with teachers 
(Stonehouse \& Gonzalez-Mena, 2004), with a key element of empowering families including strategies such as collaboration and valuing multiple ways of involvement (Souto-Manning \& Swick, 2006).

McGrath's (2007) ethnographic case study investigating mother-teacher relationships in a childcare centre found that communication between teachers and parents was integral to their building of trust, but that this was complicated by different expectations and communication styles across the two groups. The information teachers provided helped parents to build trust, but also increased teachers' power, as the parents were reliant on teachers to give them this much-needed information. Trust was threatened when there was a difference of opinion or when information was not shared in a timely manner.

\subsubsection{Goal consensus}

Goal consensus involves teachers and parents discussing and sharing information and concerns to engage in shared decision-making (Stonehouse \& Gonzalez-Mena, 2004). Synergy between parents and teachers has direct and indirect effects on children's academic and personal success (Epstein, 2001).

Hattie's (2009) meta-analysis of student achievement identified parents not understanding the language used by the school as a key barrier, where this occurred, parents were less able to make a contribution to their child's achievement.

Goal consensus can also be described as shared understandings, a concept evident in the EC literature, along with parental aspirations. Shared understandings are developed through dialogue, which can be instigated by documenting children's experiences (Loveridge, 2002). Meade et al.'s (2012) mixed method research involved two collective case studies. One case involved five centres with $100 \%$ qualified staff, whilst the other case involved five centres with 50-79\% ECE qualified teachers on their staff. The research focused on teachers' work, and the effects of this on children's learning and family participation, especially in regards to the different qualification levels of teachers in each of the case studies. The centres were randomly selected, and data collection included observations of teachers and children, analysis of assessment information, interviews with teachers and parents of target children, and a quality rating scale. Meade et al. (2012) found there were many ways that 
teachers elicited information from parents about their aspirations for their child. Some centres relied on good relationships and communication with parents, often occurring at the beginning or end of each day.

Whalley (2007) argued that if parents were going to engage in dialogue about their child's learning there needed to be a "shared conceptual framework" (p.13) between parents and teachers, highlighting the critical importance of having a shared language. Such dialogue was not always "cosy" (p.137) especially where strong views were shared and ways of thinking were challenged. However, such dialogue created a "triangulation of perspectives, in which each participant's knowledge about the child was shared, enhancing everyone's understanding of the child" (p. 157). It was important that each person involved understood the contribution and expertise individuals brought to the conversation.

A mixed method Canadian study which investigated parent-teacher interactions in culturally diverse childcare settings over a period of three years found that teachers and minority parents were unaware they had different goals for children in ECE. A total of 108 parents from nine different ethno-cultural groups and 199 teachers participated. Key findings included different perspectives between teachers and parents with respect to: reasons why minority families were less involved, goals for children in relation to cognition and social skills, and respect for authority (Bernhard, Lefebvre, Kilbride, Chud, \& Lange, 1998).

This section has provided background into Bronfenbrenner's (1979) theory relating to how communication is enhanced, and has reviewed literature in relation to the three concepts he espoused: enhanced trust, shared power, and goal consensus. The next section reviews literature and research on parent-teacher communication in ECE.

\subsection{Communication literature in relation to $\mathbf{E C E}$}

Considerable literature exists which is focused on teacher-parent communication, and its importance for parent engagement and the building of partnerships between teachers and families in ECE settings, ultimately leading to positive learning outcomes for children (eg. ERO, 2008; Loveridge, 2002; Stonehouse \& Gonzalez Mena, 2004). 
In NZ, Government has mandated parental involvement (see introduction, p. 1) in ECE settings as part of the funding requirements (MoE, 2008) indicating that it is valued. Research supports this stance, for example the Effective Provision of PreSchool Education (EPPE) project in Britain indicated that strong parental involvement, through shared aspirations and regular discussions about children's progress linked to positive learning outcomes for children (Sylva, Melhuish, Sammons, Siraj-Blatchford, \& Taggart, 2010).

Research indicates that while communication between teachers and families is a key contributor to parent engagement, it can also be fraught with difficulties from both the teachers' and families' perspectives. The following two research studies investigate this from a teachers' perspective and a parents' perspective respectively. Hughes and MacNaughton's (2001) Australian case study investigated teachers' views on parentteacher communication and relationships. This was instigated from their critical review of literature (1999) described above. Fifteen teachers participated from three different ECE centres. Teachers reported that parent involvement was difficult and complex due to the challenge in reaching shared understandings with parents about what was best for their children, and therefore they were hesitant about involving parents. However, teachers also articulated that communication with parents was essential in their work with children. Because of this complexity staff preferred informal communication such as chats at the beginning and end of the day over formal communication channels, for example, parent conferences and message books.

In contrast, Elliot's (2003) Australian qualitative study investigated parents' perceptions of quality EC care and education, as parents' views had been often missing from previous research into communication. Eighteen randomly selected EC services were approached to invite parents to participate in a focus group discussion. Thirty-six parents participated from 13 diverse centres. Three distinct themes emerged from the data; first, parents felt they were informed rather than communicated with; second, teachers did not share information that parents were interested in; and lastly there was a perceived lack of interconnectedness between home and centre experiences. 
Several of the themes that emerged from the above research studies, especially in relation to one and two-way communication, and communication about children's learning are now explored further.

\subsubsection{One-way communication}

One-way communication occurs in a straight line from sender to receiver and serves to inform or persuade, which can be seen as limited (Devito, 1995). Newsletters and notes were examples of one-way communication strategies identified in MacNaughton's (2004) action research case study, which explored changing teachers' perspectives of parental involvement. Such strategies provided limited opportunities for parents to respond.

Parents reported one-way communication, for example newsletters and parent manuals were more important than did teachers in both subsidised and private centres in Ghazvini and Readdick's (1994) quantitative study investigating the relationship between teacher-parent communication and the type of ECE setting. Parents from both types of settings felt one-way communication happened rarely, though more often than two-way communication (for example parent-teacher conversations and meetings), and that one-way communication was more important than two-way communication.

Further more, McGrath's (2007) and Bernhard et al.'s. (1998) studies (see section 2.1.3) found the most important information for parents to receive was what their child had been doing during the day, for example what they had eaten, and how they slept. Parents preferred to receive written communication, as it was not always possible to get this information from the teacher at the end of the day (Reedy \& McGrath, 2010).

What information parents wanted differed slightly in Elliot's (2003) study, where parents wanted “detailed information about children's experiences and the educational rationale behind them" (p.18). This type of information helped parents to feel part of their child's day. Instead, parents reported they often got information they didn't find valuable, as it was too general and didn't explain how it linked to or supported their child's learning. This dissatisfaction by parents was also found in Bernhard et al.'s 
(1998) study, where some parents felt written reports focused on one off happenings, rather than children's ongoing academic progress.

The quality of teacher communication with parents could be linked to the level of qualified teachers at the service. Meade et al. (2012) found that settings with $100 \%$ qualified teachers were more intentional in how they communicated and were more able to articulate children's learning to parents. These teachers had better systems for communication, and used, for example, blogs, email, and a key teacher system where a teacher was assigned to each child. These strategies increased opportunities for deeper communication with parents.

\subsubsection{Two-way communication}

Two-way communication includes feedback from the receiver to the sender. The communication is characterised by involvement and respect for the other person (DeVito, 1995). Research investigating verbal communication between teachers and parents has found such communication to be sporadic and fraught with difficulties, especially in relation to time and privacy (MacNaughton, 2004). Differences between parents' and teachers' ethnic backgrounds also influenced the quantity of conversations (Bernhard et al., 1998). These issues are discussed further below.

Bernhard et al.'s (1998) quantitative survey of 199 teachers found that teachers had daily or extensive conversations with $71 \%$ of families from the majority culture whereas they only had this level of conversations with $58 \%$ of minority families. A higher level of communication was found in a 2003 New Zealand Council of Educational Research (NZCER) (2007) survey of 531 randomly selected ECE settings, which included teachers', parents', and managers' views. The survey investigated relationships between ECE services and parents, and consultation with parents and community. Teachers reported a higher level of communication with parents about the child's interests and progress (97\%), than parents did with teachers (89\%). When asked about talking about what the child does at home this pattern was repeated with $54 \%$ of parents and $81 \%$ of teachers reporting this happened. The report suggested that these differences could be because the way teachers communicated didn't resonate with parents, or that teachers thought they communicated more than they actually did. Most parents (79\%) felt they had enough opportunity to talk with teachers. 
This high level of communication was not found in a large Canadian quantitative study (Perlman \& Fletcher, 2012). The researchers observed 1004 caregivers when they dropped their children off at centres, and found the average time caregivers spent in centres was 63 seconds. Teachers only shared or elicited information about the child with $15 \%$ of the caregivers, whereas $32.8 \%$ of caregivers provided information to the teachers. Teachers did not greet $32.6 \%$ of caregivers and $21.9 \%$ of children verbally or non-verbally. In contrast to Meade et al.'s (2012) study, Perlman and Fletcher (2012) found that increased levels of teachers' qualification or experience did not correlate with increased communication with caregivers about their child.

However, Reedy and McGrath (2010) found that even short exchanges (e.g. "hi how are you?") helped build rapport between parents and teachers, and often led to other conversations. These daily exchanges, especially in regards to sharing information about the child's wellbeing, were an important part of parents building trust in the teacher.

Such informal daily conversations were valued more by parents than the centreplanned events in Martin's (2006) research. This Irish study surveyed parents and teachers from 45 full-day mostly private ECE services about parent-teacher communication and opportunities for parents' participation. Informal communication opportunities were mostly at the beginning or end of the session, and 54\% of parents felt these helped to build a partnership with teachers.

\subsubsection{Barriers to two-way communication}

Communication between teachers and families happened mostly at drop off and pick up time of children, and these times were often difficult for both teachers and families (Stonehouse \& Gonzalez-Mena, 2004). At the end of the day when parents may have more available time, teachers were often tidying up and wanting to leave, or the more senior teachers were not available for conversations (Zellman \& Perlman, 2006).

This was also apparent in MacNaughton's (2004) action research study. MacNaughton described issues of teachers' availability: while teachers reported they were always available for parents they also said a lack of time hindered their ability to build relationships with them. Parents also spoke of lack of a 'good' time to talk with teachers: parents did not want to interrupt teaching, and arrival time was often hectic 
with teachers busy with other parents. This was supported in the NZCER (2007) survey where $25 \%$ of parents commented on the difficulty of talking within the services opening hours. McGrath's (2007) study had similar findings where, at drop off time parents were often managing two conversations simultaneously: one with the teacher and one with their child - whilst at the same time the teacher was supervising the environment and talking with the parent. Lack of appropriate space for parents to have conversations with teachers was also an issue for parents, and this affected the quality of conversations (MacNaughton, 2004).

\subsubsection{Communicating assessment information}

Sociocultural assessment involves the whole learning community, being children, families, teachers, and others (MoE, 2004a). When everyone's perspectives are communicated, listened to and valued, assessment assists the learning community to “develop ongoing and diverse learning pathways" (MoE, 2004b, p. 3) and children's learning is enhanced.

Billman, Geddes, and Hedges (2005) described portfolios as a communication tool to share planning processes and children's learning with parents. Meade (2012) further described portfolios as books often containing children's artwork, and 'learning stories' (Carr, 2001) - narrative descriptions of children's learning that show learning progression over time. As this study concentrates on the communication processes of assessment, rather than the assessment itself, literature that relates to such communication is discussed below:

The ERO (2008) evaluation of 389 ECE services in 2006 focused on the quality of these services assessment practices, and of particular interest to this study, factors that related to active and meaningful participation in assessment by parents, teachers, children, and whānau. Teachers' strategies for incorporating parents' feedback into assessments included: asking guiding questions, encouraging parents to reflect on their child's learning, and involving parents in discussions. Portfolio books along with email diaries, daily notebooks, information evenings, wall displays, and parent interviews were various ways that teachers communicated children's assessment. ERO found that just under half of the services evaluated had a limited range of input 
into the assessment, and that the feedback documented was limited and not useful to support ongoing learning.

Carr (2001) has argued that assessment processes should be credit based, focusing on dispositions, as this in itself contributes to children's developing the disposition to see themselves as learners. Meade (2012) found that the centres where all teachers were qualified had much richer descriptions of the learning, and the stories within the book were more personalised to the child. Stories also contained more parent comments and threads of dialogue between teachers and parents compared with centres with 50$79 \%$ qualified teachers.

Elliot (2003) and Meade et al. (2012) both found some parents described a lack of detail about their child's involvement or individual learning in the assessments and information provided. In the NZCER (2007) survey 20\% of parents rated information about their child's progress and the settings programme as fair or poor.

This section has reviewed ECE literature regarding one and two way communication, and communication around assessment information. The next section reports on NZ research that has investigated ICT and its use in communication between parents and teachers in ECE settings.

\subsection{Communication via ICT in ECE}

ICT has been defined as "anything which allows us to get information, to communicate with each other, or to have an effect on the environment using electronic or digital equipment” (Bolstad, 2004, p. vii).

The 1990's were a time of much debate about the value of ICT in ECE, with many teachers skeptical about the positive influence of ICT on children's learning (Hatherly, 2010). The NZCER (2007) national survey (see 2.2.2) found 78\% of teachers used ICT to produce newsletters or notices but two-way communication between teachers and parents via ICT was not reported, although just over half of managers had access to email and the internet.

In 2002 the MoE introduced the Centres of Innovation initiative, which aimed at improving quality in ECE. One of the ECE services involved was Roskill South Kindergarten, which investigated how the use of ICT in assessment increased the 
involvement of families in children's learning. Teachers used several strategies, for example loaning out the ICT equipment such as cameras to families to improve parents' involvement (Ramsey, Breen, Sturm, Lee, \& Carr, 2006).

To support the development of an ECE ICT strategy, in 2004 The NZ MoE commissioned a review of international and NZ literature relating to the use of ICT in ECE (Bolstad, 2004). The review focused mainly on research published in the previous five years. Bolstad found one of the key reasons for using ICT in ECE settings was to offer new ways to strengthen EC practice and particularly relevant to this study, ways to strengthen communication between settings and parents. A key finding of the literature review was that teachers needed to be knowledgeable about theories of learning and familiar with the types of ICT available in order to use of the ICT to effectively support children's learning. Bolstad (2004) identified further research was required to investigate how ICT could strengthen relationships between home and ECE settings.

Following Bolstad's (2004) review the ICT strategy, Foundations for Discovery was developed (MOE, 2005). This provided a framework for the implementation of ICT in NZ ECE. It highlighted that a potential benefit of ICT was to enhance communication between parents and teachers, and to better share experiences in the different settings.

To support the ICT strategy the MoE funded a three-year professional learning project with 60 ECE services, each undertaking action research projects in a self-chosen topic relating to ICT. Teams were supported with professional development via a facilitator, conference and workshop attendance, and extensive paid non-contact time. Many case studies investigated enhancing relationships between the teachers and families (Hatherly, Ham, \& Evans, 2009).

A key finding of the project was that parent-teacher relationships were enhanced when ICTs supporting two-way communication were used (Hatherly, Ham, \& Evans, 2009). Where teachers made children's learning visible through ICTs such as photos and videos, families gained a better understanding of their child's learning and parents felt reassured that their child was settled. This ability to engage with their child's learning encouraged some families to document stories from home. When this happened, children were able to see both their home and centre life equally valued. In some services families continued similar experiences and conversations at home after 
seeing the documentation of the experience. Where parents had access to their child's learning documentation via the Internet, opportunities were created to develop collaborative pieces of assessment where both home and centre could contribute. Teachers reported the immediacy of the online tools, where parents could access them any time and anywhere, facilitated this type of collaboration (Hatherly, Ham, \& Evans, 2009). However, Hatherly (2010) cautioned that to make learning visible, rather than merely sharing children's experiences via visual media such as photos and videos, teachers needed to provide a commentary that highlighted the learning that was occurring.

Such parental engagement through ICT is supported by Meade's (2012) (see section 2.1.3) study that found "the use of e-communication was transforming participation of parents in their children's early education" (p.40). Eighty percent of centres with all qualified teachers on their staff were regularly using email to share information about children's activities and learning with parents. The emails often included photos, and parents appreciated this mode of communication. ERO's (2008) evaluation of ECE assessment practices also found that having ICT available enabled teachers to include parents more effectively and make the learning more visible.

\subsection{Teacher-parent communication via ePortfolios}

This section reviews literature and research on ePortfolios and how they are used for communication between teachers and parents. While there is extensive research on ePortfolios at a tertiary level, and to a lesser extent at school level, there is minimal research addressing the use of ePortfolios within EC contexts.

From the literature search it became apparent that very little research was available that investigated two-way communication between a third party (i.e. the parent) and the teacher via ePortfolios. The central focus of school and tertiary ePortfolios was the learner as the main agent in the assessment process, so this literature was not useful for this review. Hence, literature from sources beyond academic journals have been drawn upon here, such as relevant case studies from Hatherly, Ham, \& Evans' (2009) report and articles from education magazines, in addition to articles discussed in earlier sections. 
Portfolios can have different purposes and, using the three broad descriptions of 'process, showcase, and assessment' put forward by Abrami and Barrett (2005) ePortfolios used in NZ ECE settings best fit into the category of 'process' portfolios. These are described as a purposeful collection of artifacts that tells the story of a child's effort, progress and/or achievement. Its purpose is to encourage development and growth, and support life-long learning. Thus process portfolios align best with those described by Meade (2012) in section 2.2.4.

EPortfolios can offer unique advantages over paper portfolios as they are able to integrate multimedia tools and materials to demonstrate learning, organise and categorise learning to illustrate the progress of learning over time, and are easily shared and contributed to with feedback held in one place (Abrami \& Barrett, 2005). Hartnell-Young et al. (2007) points out the importance of having a clear understanding of the purpose of the ePortfolio as this will influence the way the design is structured, as well as the content selected. When the ePortfolio is part of an overall system, rather than a discrete entity, learning is more likely to be positively affected.

In recent mixed method research involving a nationwide online survey and two case study EC centres completed by Goodman (2013a \& 2013b), her most significant finding was that through engaging with ePortfolios, parents and teachers developed communication and relationships with each other. The communication, which focused on the learning stories and recorded centre events within the ePortfolio were both more frequent and more positive than when just the hard-copy portfolio was used. Parents felt better informed about their child's learning, and this in turn led to increased confidence to approach teachers and talk about the stories. Teachers rated the positive effect of the ePortfolio communication more highly than parents.

Parents reported that having information about their child's activities at the centre also led to more meaningful conversations with their child. Teachers found that parents had also posted more of their own stories online than they did in the hardcopy profiles, and that their comments had more detail about the child's life at home, giving teachers greater awareness about the child. Having the ePortfolio online meant that more family members had access to the ePortfolio, even when they did not live locally. Teachers got to know wider whānau through the ePortfolio, and wider 
whānau greatly appreciated the ePortfolio, as it was a way they could be connected with the child's learning. Similar findings were reported for parents who travelled a lot, or who did not live with their children (Goodman, 2013a \& 2013b).

Teachers in the MoE ECE ICT project (Hatherly, 2010) whose action research projects explored ePortfolios also observed that face-to-face conversations with parents happened more readily than occurred with the hard-copy portfolios, and this deepened relationships with parents. Families overseas were also better connected to what children were experiencing at the centres.

In one such case study, conversations about what children were doing at home and the centre increased because of the ePortfolio, and affirmation from teachers further increased parent enthusiasm to engage. Teachers found this was a very different response than when they were working with just the hard-copy portfolios. They also found that some parents preferred to post their own stories, while others preferred to comment on teachers' stories. There was also a difference in the way parents wrote, for example, linking home and centre learning, or sharing events that children had participated in outside the centre. Over the year of the case study teachers noticed a change in comments made by parents, where they became more reciprocal and focused on the learning that had been extended on (Rotorua Girl's High School Childcare Trust, 2009).

Mid-way through the ECE ICT project an evaluation was completed to assess if it was meeting its intended outcomes. In relation to parent-teacher communication through ICT's, parents interviewed as part of six case studies carried out by the evaluators were positive about how ICT's supported continuity between the centre and home. It was found however, that this communication was generally "not focused on children's specific learning interests" (Cherrington et al., 2009, p.14). When facilitators were asked to give examples of ways ICT supported parents to be more engaged in their child's learning, these were more likely to be about what children were doing, but there was less evidence to the "extent to which the children's learning is foregrounded in these communications" (p.18).

This literature review has explored three key concepts for enhanced two-way communication: trust, shared power, and goal consensus. It has also examined ECE communication literature and research, first focusing broadly on one-way and two- 
way communication between teachers and parents, and then more specifically on communication in regards to assessment, communication through ICT, and lastly ePortfolios. This literature review has highlighted gaps in knowledge about the effective use of ePortfolios in ECE, especially in regards to two-way communication between parents and teachers that support children's learning, which this study hopes to address. The following chapter presents the methodology used in this study. 


\section{CHAPTER 3: METHODOLOGY}

This chapter outlines the methodological approach used in this study. Firstly the rationale for the approach used is explained, followed by the methods of data collection. Ethical considerations are described next, followed by the explanation of validity measures. Finally, data analysis approaches are described, including inductive and deductive approaches to analysis.

\subsection{Rationale for research paradigm and methodology}

This study sits within a constructive-interpretivist paradigm. This paradigm acknowledges the possibility of many different reasons for people's actions, and emphasises a detailed account of the issues, rather than making broad generalisations (Mukherji \& Albon, 2010). It is context specific and the researcher reports on the participants' interpretations of the situation. It also acknowledges the researcher's own experiences and background can influence the interpretation of findings (Denzin \& Lincoln, 2000). This paradigm is often used in educational research, where educationalists are interested in understanding participants' experiences.

Qualitative methodology supports a constructive-interpretivist paradigm (Denzin \& Lincoln, 2000) and forms the basis of this study. This methodological approach explores a phenomenon to gain an in-depth understanding, and enables the understanding of multiple realities in a naturalistic setting. People's feelings, relationships, actions, and how they express themselves are all relevant sources of data in qualitative research. Data is richly descriptive and tells the story of the different participants' reality. Patterns from the data are identified and inductive reasoning is used to understand them (Newby, 2010, p.46).

To strengthen the trust-worthiness of this study both qualitative and quantitative data collection methods were used. A mixed methods approach brings together two very different viewpoints. For example, a single reality, objectivity, and deduction are the focus of quantitative research, and multiple realities, subjectivity, and induction are the focus in qualitative research. A pragmatic approach helps describe mixed research methodology, where the focus is practical problem solving, using what works best to answer the research question (Newby, 2010). Using this approach in collecting and 
analysing data can provide a better understanding of the research problem than by using either method by itself (Creswell, 2012).

\subsubsection{Case study}

Case study can be seen as a general and inclusive approach to qualitative research, where multiple methods and data sources are used to answer the research question (Johnson \& Christensen, 2012). It is a specific and detailed study of a particular individual or group (Lichtman, 2006) and focuses on describing the case's characteristics, how it operates, and sets to answer research questions about the case. It is distinguished by the ability to ring- fence the phenomenon within a particular defined context, often referred to as a bounded system (Merriam, 2012).

I chose a case study design approach as I was interested in understanding families' and teachers' experiences in using ePortfolios, especially as ePortfolios were fully integrated into teachers' everyday practice and I was familiar with the centre culture and operations.

The bounded system of this single case included all those at the selected ECE centre who used the web based ePortfolio platform at the start of the research. Participants in this research were parents, wider whānau and teachers. While the children's ePortfolios were included as a data source, children did not participate in this research.

Yin (2009) describes three factors in choosing case study as the preferred method: when the research question asks 'why' or 'how', when the researcher has limited control over the events, and when the focus is of a phenomenon within a real-life context. This research study meets all three of these criteria. As ePortfolios are a new phenomenon in ECE, the centre used in this study offered a rare insight into how this tool had affected communication between teachers and families, especially as the centre had used ePortfolios since 2012.

Newby (2010) describes three different types of case study: exploratory, explanatory, and descriptive. Because ePortfolios are a new phenomenon in ECE, the case study was exploratory in nature. It is hoped this study will give an understanding of how ePortfolios are being used to facilitate communication in one ECE centre, and that 
this might offer insights to other teachers already using ePortfolios, or to those considering using ePortfolios in their ECE service.

This investigation aims to contribute to knowledge on how ePortfolios enhance parent-teacher communication in ECE. The following research questions have been identified for this study:

1. How do ePortfolios facilitate communication between families and teachers in an EC centre?

2. What type of communication is fostered through the use of ePortfolios in an EC centre?

3. What impact does communication through the use of ePortfolios have on teacher-parent relationships and children's on-going learning?

4. How do teachers' values and beliefs about communicating with families influence communication through ePortfolios in an EC centre?

\subsection{Participants}

The case study centre chosen for this study had been using ePortfolios for just over two years before I started my study. I chose this centre because ePortfolios had been used for an extended time, considering the newness of the platform, and were embedded into the centre's assessment practices.

This centre was based in a suburb in an urban NZ city. It catered for mainly working parents, and was open all year for full day attendance. It was situated in a school area classified as decile 10, the highest rating level in relation to the income of the people living in the area. The centre was run as a not-for-profit service, employed all degreeor diploma-qualified ECE teachers, and catered for 25 children from 2-5 years old. Children could attend full or part time, and each child was assigned a 'whānau group' teacher, who was responsible for settling the child and building initial relationships with the parents. All parents and teachers had access to email. The centre was well resourced with digital cameras and computers, and there was a computer and data projector available to children. 
All seven teachers and 29 parents from the 33 families attending the centre agreed to participate in the study. Wider whānau who were registered on the children's ePortfolio of participating parents were invited to take part in an online survey and 13 completed this.

\subsection{Data sources for this study}

Case study method recommends collecting data from a wide range of sources (Yin, 2009). Five data collection methods were used initially: an online survey, analysis of exemplar learning stories and in-depth analysis of four children's ePortfolios, semistructured interviews, focus group interviews, and observer as participant observations. Analysis of ePortfolio learning stories and subsequent comments from teachers and families allowed themes on the influences of online communication to emerge. These themes helped inform the development of a survey for all teachers and families at the centre. Whilst surveys are not usually part of case study methods, this enabled data collection from a wider group not available through interviews, due to time constraints and the size of this study. The survey also served as a source to find willing teacher and parent participants for semi-structured interviews that met purposive sampling criteria. Individual interviews enabled personal perspectives to be heard, and to explore emerging themes in more detail. Prior to the parent interviews, children's ePortfolios belonging to the interview participants were re-examined in greater detail. Figure 3.1 shows the process of data collection, including the quantitative and qualitative elements, and the chronological order of the data collection. 


\section{Process of data collection}

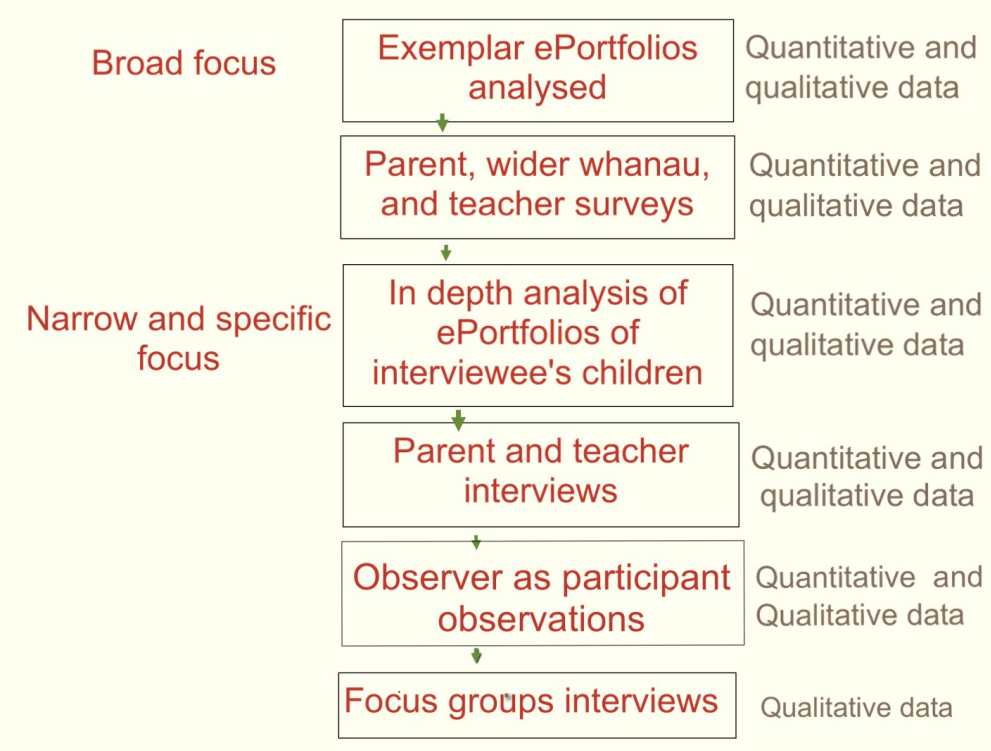

Figure 3.1: Process of data collection

The five data collection methods used are described in more detail below:

\subsubsection{Document analysis}

Children's ePortfolio stories and subsequent online comments from participating teachers $(\mathrm{N}=7)$ and families $(\mathrm{N}=29)$ were examined and information collected on how many comments had been written for each story by teachers, parents, and wider whānau.

In the table below individual stories were stories written by the teachers to one child. Group stories were written to a group of children. Group stories were divided into three categories depending on how many children were included in the story: 2-5 children, 6-19 children and the whole centre group of children. Home stories were stories written by parents and wider whānau. Overall 847 (69\%) of the learning stories analysed included at least one on-line comment made by a teacher, parent or wider whānau. 
Table 3.1: Number of learning stories commented on by participants

\begin{tabular}{|l|c|c|c|l|}
\hline & 0 comments & $1-4$ comments & $5+$ comments & Total \\
\hline $\begin{array}{l}\text { Individual } \\
\text { stories }\end{array}$ & $224(39 \%)$ & $334(57 \%)$ & $22(4 \%)$ & $580(100 \%)$ \\
\hline $\begin{array}{l}\text { Group stories } \\
2-5 \text { children }\end{array}$ & $119(29 \%)$ & $259(62 \%)$ & $38(9 \%)$ & $416(100 \%)$ \\
\hline $\begin{array}{l}\text { Group stories } \\
6-19 \text { children }\end{array}$ & $11(13 \%)$ & $53(62 \%)$ & $22(26 \%)$ & $86(100 \%)$ \\
\hline Centre stories & $23(25 \%)$ & $42(45 \%)$ & $28(30 \%)$ & $93(100 \%)$ \\
\hline Home stories & $2(4 \%)$ & $39(76 \%)$ & $10(20 \%)$ & $51(100 \%)$ \\
\hline Total & $379(31 \%)$ & $727(59 \%)$ & $120(10 \%)$ & $1226(100 \%)$ \\
\hline
\end{tabular}

Having completed the initial analysis, I focused on a selected number of exemplar stories for further analysis. As I wanted evidence of substantial dialogue, I chose stories with five of more comments. Ten percent $(\mathrm{N}=120)$ of all the stories analysed fitted this criteria.

Twenty-two individual stories from across eight children's ePortfolios had five or more comments. The story with the most comments from each of these eight children and stories with four comments from other children $(\mathrm{N}=8)$ were included resulting in a total of 16 stories being selected for further analysis. This gave a broad range of children's stories with comments, rather than using stories from a limited number of families who commented more frequently. Where these eight other children had more than one story with four comments the most recent one was included. The number of comments in each story was between four and seven.

Eighty-eight group stories had five or more comments. Many of these stories had multiple contributors to the comments, and not all contributors had given consent for the story to be used. Therefore from these group stories only those where all participants had given consent were included. This resulted in 23 group stories written to 2-9 children for further analysis. There were between five and ten comments in 
each of these stories. These 39 stories (being 16 individual stories and 23 group stories) are referred to as exemplar learning stories in the following sections and chapters when referring to the data sets.

Further analysis was undertaken of four individual children's ePortfolios whose parents were involved in the interviews. This was to investigate continuity of each child's learning and whether the online dialogue had contributed to this over time. Stories and comments were analysed to investigate how comments had been responded to (e.g. by way of further comment or story) and how this contributed to learning evidenced in the ePortfolio.

The table below shows the numbers of stories written by teachers, and how many comments were written on each child's ePortfolio:

Table 3.2: Numbers of stories and comments by teachers and parents

\begin{tabular}{|l|l|l|l|l|l|l|}
\hline \multicolumn{1}{|c|}{ Childs ePortfolio } & \multicolumn{2}{|c|}{$\begin{array}{c}\text { Total number of } \\
\text { teacher stories }\end{array}$} & \multicolumn{2}{c|}{$\begin{array}{c}\text { Number of } \\
\text { Comments by } \\
\text { parents }\end{array}$} & \multicolumn{2}{|c|}{$\begin{array}{c}\text { Number of } \\
\text { comments by } \\
\text { teachers }\end{array}$} \\
\cline { 2 - 8 } & individual & group & individual & group & Individual & group \\
\hline Mindy (always) & 10 & 65 & 11 & 31 & 2 & 10 \\
\hline Susie (frequent) & 20 & 145 & 19 & 41 & 11 & 12 \\
\hline Kirsty (frequent) & 29 & 196 & 9 & 36 & 7 & 14 \\
\hline Lou (occasional) & 17 & 192 & 13 & 13 & 5 & 5 \\
\hline Total & $\mathbf{7 6}$ & $\mathbf{5 9 8}$ & $\mathbf{5 2}$ & $\mathbf{1 2 1}$ & $\mathbf{2 5}$ & $\mathbf{4 1}$ \\
\hline
\end{tabular}

Mindy's mother described herself as someone who always commented on a story, both Suzie's and Kirsty's mothers described themselves as frequent commenters, and Lou's mother described herself as an occasional commenter. 


\subsubsection{Online surveys to all teachers and families}

Two online surveys gathered data to help answer the research questions, for example, how parents, wider whānau and teachers felt ePortfolios helped communication, relationships, and the understanding of children's learning.

There were separate online surveys for teachers and families. These were similar, so only the teachers' survey has been included in the appendices as it had further questions (see appendix 1). The first question collected information on the demographics of the respondents. The second question asked respondents to rate the usefulness of the ePortfolio across seven items relating to communication, relationships, and children's learning, using a four point rating scale, and was followed by an open-ended question where respondents were asked to give examples. An instrument developed by Goodman (2013a) in a previous study on parent engagement in ePortfolios was used to guide this section. These were followed by seven fixed response questions, of which six gave opportunities for respondents to elaborate on their response.

The teachers survey had eight questions not included in the family survey (question numbers 10-17). These investigated strategies teachers used to engage parents in communication via the ePortfolio, and their values and beliefs in regards to communicating with parents.

Question 18 was designed to measure interpersonal trust between teachers and parents, and was adapted from Janssen et al.'s (2012) instrument, which measured teacher-parent trust in primary schools. This was modified to better suit ECE settings, and fewer questions were used to keep the survey at a reasonable length. Two items from each of Janssen et al.'s five trust categories were included. The final question gave participants opportunity to add any further comments.

The family survey was reworded to focus on the parents' and wider whānau perspective rather than the teachers. Parents and wider whānau were identified by way of an extra question, where they needed to indicate which category they belonged to.

Qualtrics (an online survey tool) was used to email the survey link to all email addresses that were on each participating child's ePortfolio $(\mathrm{N}=103)$. These email addresses generally included family members who had been invited by parents to 
access the child's ePortfolio. The online survey included an introductory information letter and consent statement (appendix 2) explaining the research as wider whānau were not included in the initial information and consent process (appendices 3 and 4). From the 29 families that agreed to participate in the research, there was a $32.6 \%$ $(\mathrm{N}=33)$ response rate to the family survey, made up of 20 parents (one parent from each family) and 13 wider whānau. The survey was emailed to the seven teachers who all responded.

The survey was piloted with two teachers and one parent who had previously used the ePortfolio at the centre. Reminder emails were sent one week and three weeks after the original email and a thank-you email was sent automatically after the respondent had submitted the survey.

Numbers of responses to individual questions did not always match the total number of participants as some chose not to answer all questions. Table 3.3 below shows the largest group of parent and wider whānau respondents had been using the ePortfolio for 1-2 years, so were familiar with its use and were beyond the initial novelty of using it. Teachers had an almost even spread of time using the ePortfolio from seven months to three years.

Table 3.3: Time child had ePortfolio or teacher had been using it

\begin{tabular}{|c|c|c|c|c|c|}
\hline & $\begin{array}{c}0-6 \\
\text { months }\end{array}$ & $\begin{array}{c}7-12 \\
\text { months }\end{array}$ & $1-2$ years & $\begin{array}{c}2.1-3 \\
\text { years }\end{array}$ & Total \\
\hline Teachers & 0 & 2 & 2 & 3 & 7 \\
\hline Parents of child & 1 & 2 & 13 & 4 & 20 \\
\hline $\begin{array}{c}\text { Wider whānau of } \\
\text { child }\end{array}$ & 0 & 1 & 6 & 5 & 12 \\
\hline
\end{tabular}

\subsubsection{Semi-structured individual interviews}

Purposive sampling was used to select five parents and three teachers to interview to collect a wide range of perspectives (Johnson \& Christensen, 2012). Purposive sampling was based on participants' responses to questions about their commenting (high commenting, non/minimal commenting, change in number of comments made, and change in type of comments made). 
Five parents indicated initial interest in participating in the interview via the survey, although one declined once further consent was sought, leaving four parent participants for the individual interview. One parent represented the self-reported category occasional commenter, two represented frequent commenters, and one represented the group whenever I receive a story. The question on shifts in type or amount of comments was not used as a criterion for selection as only one participant responded that there had been a shift in either of these categories but did not want to be interviewed. Each interview was approximately one hour long and was conducted by either the research assistant or myself depending on the prior relationship I had with the participant (see section 3.4 for more information). To maintain consistency an interview protocol was developed (appendix 5). The interview questions were framed around the research questions, together with questions developed from themes emerging from the survey data. Interviews were transcribed by a transcriber who had signed a confidentiality agreement (appendix 6) and pseudonyms were used to ensure anonymity.

Four teachers indicated their interest in participating in this phase of the research. The research assistant selected three teachers to interview based on their survey responses regarding how often they commented, and if their commenting had changed over time. This ensured a spread in types of commenters. The research assistant interviewed all three teachers and their identity was known only to her and the transcriber, following the ethics protocol described in section 3.4.

\subsubsection{Observer as participant observations}

The research design included observations of conversations between interviewed parents and teachers. This was more difficult than intended as the child of one participating parent left the centre before their $5^{\text {th }}$ birthday and was not available, another was mostly picked up by the father when the mother was the interview participant, and another was picked up at varied times so it was difficult to be in the centre when the parent was there. Those observations able to be collected showed considerable dialogue between the parents and teachers but due to difficulties in hearing the topic of conversation these were not recorded. Given the limited observations obtained, these have not been used in the study. 


\subsubsection{Focus group interviews}

The purpose of the focus group interviews was to share the initial findings and emerging themes, and to check participants' responses had been interpreted correctly. It was also an opportunity to ask further questions that surfaced from the individual interviews. There was a separate focus group interview for parents and teachers.

The research assistant conducted the focus group interviews whilst I recorded, following the ethical guidelines described later in the chapter. It did prove difficult not to become involved in the interviews, as participants asked questions that the assistant was unable to answer, as she had not been involved in all the data collection or analysis.

All seven teachers were invited to attend the focus group interview, and four participated. Because I didn't know the identity of the teacher interviewees I didn't know if the teachers in the focus group interview were the same as those who participated in the interview. Three parents from the individual interviews participated in the focus group interview. The one parent who didn't attend represented the group commenting frequently.

\subsection{Ethical considerations}

Ethical approval was gained from the Victoria University of Wellington Human Ethics Committee before approaching the participants or conducting the study (SEPP/2013/74 RM 20286, received 18/11/13).

Informed consent was first gained from the Centre's management committee (appendix 7). Informed consent was then gained from teachers and parents (see appendix 3, NB: parent information sheet is very similar to the teachers information sheet. Appendix 4 is of teachers and parents consent forms) before children's ePortfolios were accessed and online surveys emailed out. A second level of informed consent was gained for interview and focus group participants (appendix 8).

To protect the privacy of the participants all data was kept confidential to myself, the research assistant, the transcriber, and my supervisor. The research assistant signed a confidentiality agreement (appendix 9). Pseudonyms were used to protect the 
anonymity of the centre, participants, and children, and quotes used in this report do not identify participants. Each quote is referenced with a code that identifies the data source, and where it was found within it, for example, PS.6.1, for parent survey, $6^{\text {th }}$ question, $1^{\text {st }}$ comment (see appendix 10 for table outlining data source codes).

Because of my professional background and to ensure I did not influence participants' responses, the Ethics Committee required I was not involved in the individual interviews of all teachers and any parent I knew prior to beginning of the research. The Ethics Committee also required that I did not know the identities of the teacher interview participants, so the research assistant liaised with the transcriber and pseudonyms were used on the teacher interviewee transcripts sent to myself.

At the interviews, the research assistant or myself checked that the interviewee had received and read the Participant Information Sheet and asked if they had any questions about this information. Teachers were told their identities would be kept anonymous on the transcripts, and all participants were told that pseudonyms would be used in the thesis. It was explained that the transcripts would be sent to them to read and if there was anything they wanted to add, change, or delete this would be done without justification or explanation on their part.

I needed to consider disclosure in the focus groups between participants, and ensure that all views were respected and validated. As part of the introduction the research assistant made it clear that participants did not need to agree with each other, and to let everyone have a chance to be heard. She also gave time for everyone to introduce themselves as they may not have known each other well.

\subsection{Trust worthiness and reliability}

In qualitative research validity is about judging the extent that the research has captured important features and analysed them with integrity (MacNaughton, Rolfe \& Siraj-Blatchford, 2001). Several strategies were used to ensure the integrity and trustworthiness of this study.

The quantitative data collection methods used alongside qualitative methods provided precise numerical data that was relatively independent of myself, and also gave greater triangulation of the data (Johnson \& Christensen, 2012). This enabled quantitative data collected from the learning stories and participants' survey to be 
compared and integrated alongside the analysis of participants' open-ended responses in the surveys, interviews, and focus group interviews to better understand how ePortfolios facilitated communication. The quantitative data collection was carried out simultaneously with the qualitative data collection.

\subsubsection{Descriptive validity}

Descriptive validity is the factual accuracy of the account given by the researcher (Johnson \& Christensen, 2012). To increase descriptive validity a research assistant was employed to interview all teachers and parent participants who had a previous relationship with me. This was done because I had involvement with the centre before starting the research study, and this relationship could have influenced the way participants responded.

\subsubsection{Interpretive validity}

Interpretive validity is accurately reporting the meaning given by participants. This was enhanced as I had 'insider' understanding of how the centre operated, so was better able to interpret participants' comments as they were intended, though this was limited to some extent by only being able to conduct one of the interviews. Asking interview participants to check their transcripts for accuracy, and sharing my interpretations of the data with the focus groups further reduced the chance of miscommunication or misunderstanding (MacNaughton, Rolfe \& Siraj-Blatchford, 2001).

\subsubsection{Reflexivity}

Reflexivity is reflection by the researcher in regards to her biases and personal views. Researcher bias is an established threat to qualitative research (Johnson \& Christenson, 2012) so the bias of the researcher needs to be acknowledged. In regards to my potential bias pertaining to this study, I was a voluntary advisor for the ePortfolio company used by the centre up until the time of undertaking the interviews and focus group interviews. After personally using ePortfolios I believe that the ePortfolios had made a difference to my communication with parents, which is what inspired me to undertake the research. My background both in ECE and in the case study centre, could have also brought bias to the way that the data was gathered and interpreted (Lichtman, 2006). 
Several strategies were used to address this bias. I intended to use purposive sampling that included negative examples, such as interviewing parents who did not comment. Unfortunately, no parents willing to be interviewed fitted this criterion. A reflective journal as a tool to monitor bias and self-awareness was maintained (Johnson \& Christenson, 2012). Fortnightly conversations with my supervisor were also a way of discussing and being alerted to potential bias.

\subsubsection{Triangulation}

Triangulation via a range of data collection methods helps to increase validity of the case study findings (Johnson \& Christensen, 2012). Using both qualitative and quantitative data collection methods further strengthened triangulation by comparing results in a complementary way (Newby, 2010).

\subsection{Data analysis}

Both qualitative and quantitative data analysis were used. These are explained in more depth below:

\subsubsection{Qualitative data analysis}

Data analysis in qualitative research is a way of creating order out of often complex and rich data, shaping it so it can be interpreted in a way that helps to answer the research question (Newby, 2010). There are many approaches to doing this, and they often involve an inductive process. This approach starts with the data, where the researcher firstly gets a general sense of the data, and then moves on to create descriptions or themes to develop an understanding of the phenomena (Creswell, 2012). Data collection and analysis are often done at the same time, and it is not always a linear process (Johnson \& Christensen, 2012). The data analysis approach used in this study is referred to as 'thematic analysis'.

\subsubsection{Thematic analysis}

Thematic analysis has been described as "a method for identifying, analyzing and reporting patterns (themes) within data” (Braun \& Clarke, 2006, p. 79). It is a flexible approach, and enables the researcher to respond to unanticipated evidence as themes and patterns are discerned (MacNaughton, Rolfe \& Siraj-Blatchford, 2001). Braun 
and Clarke (2006) and Creswell (2012) provide very similar and useful phases of thematic analysis, which are described below in relation to my study.

Phase one involved becoming familiar with the data. I initially read both the quantitative and qualitative data in all the surveys to gain an overview of the data and familiarise myself with potential themes that were emerging. Each participant group was analysed separately to begin with so any differences in the groups of participants would be more apparent.

The next phase involved the generation of initial codes from the data. I extracted the qualitative data from the surveys and using the computer software, nVivo, coded the participants' responses looking for patterns.

Phase three involved grouping similar codes together to create themes. At this point codes could become themes, and often there were relationships between themes, as well as different levels of themes (Braun \& Clarke, 2006).

The final phase involved reviewing and refining the themes. There were two levels to this phase: first themes were checked against the coded extracts to ensure the theme reflected the data within it. This often involved generating, shifting and reclassifying themes (Braun \& Clarke, 2006). I spent a lot of time going back and forward between the data, codes, and themes in an iterative process as I developed a more in-depth understanding of the data. Where similar theme headings were apparent in the different participant groups, these were made consistent over all the groups to avoid confusion. Codes rarely used were reanalyzed to see if there was another code or theme they could be combined with, or kept because they were significant. Braun and Clarke (2006) remind us that coding is an ongoing and organic process, and there will be much re-coding at this stage.

Codes and themes identified in the earlier analysis of the survey were used with the individual interviews and ePortfolio document analysis to see if they were reoccurring. The four steps above were repeated with these data. This was done in a more limited way with the focus group interviews, as notes rather than a verbatim record were kept. Also much of the focus group interview was spent checking the validity of the findings so far, so this generally did not add new data. The theme 
descriptions for the parent survey are included in appendix 10 as an example, and are indicative of the other data sources.

In addition to the inductive analytical approach outlined above, a thematic deductive analysis was used over all the data sets to investigate how the communication theoretical framework described in the literature review in regards to trust, balance of power, and goal consensus was evident in the data.

\subsubsection{Quantitative analysis}

Many of the survey questions and exemplar stories provided quantitative data. I have reduced the quantitative data by using simple descriptive statistics, often displaying the data visually using tables and graphs (Johnson \& Christensen, 2012).

\subsection{Conclusion}

This chapter has described the methodology used in this study. A qualitative research approach is used, located within a constructivist-interpretivist paradigm. This is where meaning is constructed from the lived experiences of the participants as they interact within the environment.

In order to answer the research questions, a case study approach has been chosen. Four data collection methods are undertaken and thematic analysis is used to identify patterns and emerging themes.

In the next chapter, the findings are presented and grouped into three themes emerging from the inductive thematic analysis: benefits and drawbacks of communication via the ePortfolio; ePortfolio tools that either enabled or frustrated communication; and content of communication evident through online comments. The findings from the deductive thematic analysis using the two-way communication theoretical framework from Bronfenbrenner are then presented. 


\section{CHAPTER 4: RESULTS}

This chapter draws on data collected through the methods described in the previous chapter to report findings of this research. The first three sections describe the key themes that emerged from the analysis of the data sets: the benefits and drawbacks of communication via the ePortfolio; the enablers and barriers created by the ePortfolio platform and associated tools; and the types of communication evident through online comments. The final section presents the results relating to the theoretical framework of two-way communication described in the literature review, being: enhanced trust, a balance of power, and goal consensus.

\subsection{Benefits and drawbacks of communication via ePortfolios}

This section describes key benefits and drawbacks of communication between different groups in the centre's learning community using ePortfolios. Benefits included: being informed by reading the stories, connections made between ePortfolio and face-to-face conversations, building relationships, and supporting children's learning. Drawbacks included the potential for miscommunication in group online communication, and how online communication influenced the on-going engagement of teachers and parents with each other, potentially negatively impacting those families not engaging with ePortfolios.

Results in this section draw on the data from the parents', wider whānau and teachers' online surveys, and the parents' and teachers' interviews and focus group interviews. Where relevant it also reports data from the exemplar learning story analysis.

\subsubsection{Being informed}

A key finding from the surveys and interviews was parents and wider whānau being well informed through the ePortfolio, about their child's experiences and learning while at the centre. 
Table 4.1: Extent ePortfolios helped parents and wider whānau understand their child's learning at the centre

\begin{tabular}{|c|l|l|l|l|l|}
\hline & Not at all & Occasionally & Quite a lot & A great & Total \\
& & & & & deal \\
\hline Parents & 0 & 0 & 12 & 8 & 20 \\
\hline Wider whānau & 0 & 0 & 5 & 8 & 13 \\
\hline Total & 0 & 0 & 17 & 16 & 33 \\
\hline
\end{tabular}

Table 4.1 showed that $100 \%$ of the parents and wider whānau who responded to the survey felt that the ePortfolio helped them understand their child's learning at the centre quite a lot or a great deal. This was supported by the qualitative data in the survey where $65 \%(\mathrm{~N}=13)$ of parents and $77 \%(\mathrm{~N}=10)$ of wider whānau described how they were well informed about their child's experiences at the centre through the ePortfolio, and the difference this had made in terms of knowledge about what their child was doing when they weren't with them. For example, one parent commented:

We've loved receiving the updates of what Colin has been up to, and are thrilled with the posts submitted - everything ranging from simple tasks, funny stories, and group activities - the teachers at [the centre] keep us up to date on everything and we love it (PS.4.15).

This was also supported by three parents in the interviews, as in the following example:

I think that it's really nice to know what they're actually doing during the day, because sometimes you're in a rush in the mornings and the evenings and so you don't always get that quality time to stop and talk to the teachers on a regular basis...(PI.2.1300).

Being informed about their grandchildren's experiences was particularly evident for a group of grandparents who didn't have regular contact with them: 
As I live away from Wellington and am not in daily contact I find this an informative and interesting window into my grandchild's learning and development (WWS.16.9).

Some described a connection with their grandchild that the ePortfolio afforded:

As I live in the UK, seeing my grandsons develop ... is an invaluable connection for me to see them growing up and learning so naturally. It really is amazing. I am grateful for it (WWS.4.1).

While it was not possible to know how many times parents and wider whānau viewed $^{1}$ the stories, the initial learning story analysis carried out in this study showed that $69 \%$ of stories were commented on, and $96.5 \%(\mathrm{~N}=28)$ of participating families commented a minimum of once on at least one story, indicating positive levels of engagement.

Parents interviewed said the individual stories and small group stories were most useful for finding out about their child's learning, as one parent described:

Anita: But in terms of benefit to us, I think the strongest ones [stories] would be the one-on-one or the small group Interviewer: Small group. And what about the group ones?

Anita: They're good in a different sense - not so much about our child's learning... They're just more general ones where they tell us a bit more about what's going on and let us have conversations with her about what she did (PI.3.3788).

\subsubsection{Connecting face-to-face conversations}

Analysis of the surveys and interviews indicated that online communication supported and enhanced face-to-face conversations between teachers and parents, teachers and teachers, and families and children. Each of these is described in more detail below.

\footnotetext{
${ }^{1}$ This feature has since been added to the ePortfolio platform
} 


\subsubsection{Teachers and parents}

In the surveys all teachers, parents, and wider whānau felt that the ePortfolio helped strengthen communication between home and the centre, with $75 \%(\mathrm{~N}=15)$ of parents and $100 \%(\mathrm{~N}=7)$ of teachers responding saying it helped quite a lot or a great deal.

Table 4.2: Extent ePortfolios strengthened communication between home and centre

\begin{tabular}{|l|l|l|l|l|l|}
\hline $\begin{array}{l}\text { Strengthen } \\
\text { communication between } \\
\text { centre and home }\end{array}$ & $\begin{array}{l}\text { Not at } \\
\text { all }\end{array}$ & A little & $\begin{array}{l}\text { Quite a } \\
\text { lot }\end{array}$ & $\begin{array}{l}\text { A great } \\
\text { deal }\end{array}$ & Total \\
\hline Teachers & $0 \%(0)$ & $0 \%(0)$ & $43 \%(3)$ & $57 \%(4)$ & $100 \%(7)$ \\
\hline Parents & $0 \%(0)$ & $25 \%(5)$ & $40 \%(8)$ & $35 \%(7)$ & $100 \%(20)$ \\
\hline Wider whānau & $0 \%(0)$ & $29 \%(2)$ & $0 \%(0)$ & $71 \%(5)$ & $100 \%(7)$ \\
\hline Total & $0 \%(0)$ & $21 \%(7)$ & $32 \%(11)$ & $47 \%(16)$ & $100 \%(34)$ \\
\hline
\end{tabular}

One teacher surveyed elaborated:

The [ePortfolio] often prompts conversations in person about what children have been learning. It is often a great conversation starter with parents when they come to drop off or pick up their children, at other times parents will be the person to initiate discussions when they come into the centre (TS.3.1).

This was also noted in two of the teacher's interviews, for example:

Since [the ePortfolio], it's helped me to build relationships, and then so once you've had a dialogue online, then it's easier to go up to someone and just chat to them about their child (TI.2.4823).

In the survey teachers were asked about the strategies they used to encourage communication via the ePortfolio. They felt the most successful were asking questions within the story and acknowledging the parents' online comments. Other strategies noted were acknowledging the teacher wasn't the expert, writing more 
individual stories, and having face-to-face conversations with parents about the stories written.

Parents surveyed explained that face-to-face conversations often happened with teachers as part of the teachers' response to their online comments. In the parent interviews all four parents felt that the online conversations strengthened the face-toface conversations at the beginning and end of the day:

\begin{abstract}
A teacher had posted a story about a child exploring physical limits outside, which was a surprise to us. Cos one of the photos was her planking [lying horizontally] across a bridge [on handrails]. Like what? So that was interesting in terms of our comments back to convey the 'whoa what's she doing' but also to hold ourselves back, actually that's a good thing, we shouldn't freak out. But then that led to a further conversation in debriefs at the end of the day with that particular teacher about what her interests were in outside and how [the teacher] noticed this developing her confidence and so forth and other observations that teacher made about other physical activities and things. So that as quite a good way of a conversation starter almost (PI.4.2765).
\end{abstract}

Another conversation starter was when new teachers shared their 'profile' on the ePortfolio. These were more likely to be read by parents than when they were displayed on the wall in the centre, and helped to spark conversation.

\title{
4.1.2.2 Teachers and teachers
}

The survey showed that six of the teachers felt that the ePortfolio had helped their communication about children's learning with other teachers quite a lot or a great deal. One teacher elaborated on this later in the survey:

....I think [the ePortfolio platform] has supported me in having conversations with teachers about the stories they have written as well as the stories I have written. These conversations are usually more likely to be in person than posted on [the ePortfolio]. These conversations often start with "have you seen the story I wrote about....." or "I saw the story you wrote about" (TS.3.1). 
The teachers' interviews and focus group interview was more focussed on commenting on each other's stories online:

I think the [comments] I enjoy making the most are probably the ones where you can comment on when you've noticed the same thing...(TI.1.1143).

\subsubsection{Families and children}

All parents interviewed talked with their child about the stories on their ePortfolio, and had shown their child their ePortfolio, for example:

Suzie and I discuss her [ePortfolio] stories all the time... Suzie will see through my iPhone or the iPad at home what's been going on. And she interacts with it as well, which is really good. Because she sees all her friends and what she gets up to and she watches all her videos of her doing stuff on [the ePortfolio] and she loves it - she thinks it's great (PI.1.660).

Whilst in the survey only one parent noted that she talked with her child about the stories and that she would post the child's comment online.

In the survey two grandparents said that they were able to have conversations with their grandchildren about what they had been doing at the centre, through reading the stories in their ePortfolio, for example:

I don't see what happens at day care at all in person so is neat to see what Liam has been up to and am able to talk to him about what he has been doing and his friends after I read his stories. (WWS.4.3).

\subsubsection{Building relationships}

The surveys asked participants the extent the ePortfolio had helped strengthen the relationship between teachers and parents. Table 4 below shows teachers' and parents' responses: 
Table 4.3: Extent ePortfolios strengthened parent-teacher relationships

\begin{tabular}{|l|l|l|l|l|l|}
\hline Group & Not at all & A little & Quite a lot & $\begin{array}{c}\text { A great } \\
\text { deal }\end{array}$ & Total \\
\hline Teachers & 0 & $14 \%(1)$ & $57 \%(4)$ & $29 \%(2)$ & $100 \%(7)$ \\
\hline Parents & 0 & $30 \%(6)$ & $45 \%(9)$ & $25 \%(5)$ & $100 \%(20)$ \\
\hline Total & 0 & $26 \%(7)$ & $48 \%(13)$ & $26 \%(7)$ & $100 \%(27)$ \\
\hline
\end{tabular}

All parents' and teachers' responded that they felt the ePortfolios helped strengthen the teacher/parent relationship to some extent, with $26 \%(\mathrm{~N}=7)$ feeling the ePortfolio had strengthened the relationship a great deal. This was also evident in all the parent interviews when participants were asked how the communication via the ePortfolio had affected their relationship with the teachers, as in this example:

I don't know whether it was because of [the ePortfolio] but we definitely felt quite positive to and had quite a strong connection with one of the teachers who was probably the most regular poster about our child - who wasn't her whānau group teacher, but was just someone I think who we appreciated the stories that she posted about our child, and was a teacher who had been also quite active in giving us verbal debriefs at the end of the day, particularly while [our child] was settling in (PI.4.3078).

One parent noted that commenting online had sped up building relationships with teachers. Another described how the ePortfolio had "broken the ice" and led to more face-to-face communication. Teachers' interview responses also spoke of strengthened relationships, with two teachers describing how it provided another avenue for communication. One teacher gave an example where parents engaged with a small group story about worm farming and sustainability, resulting in both online and face-to-face conversations with parents providing information to the teacher about what to do next and bringing in resources. She explained how exciting it was that everyone was involved in this particular learning journey.

In both the survey and interviews teachers described how they were better able to build relationships with wider whānau they didn't always get to meet face-to-face, as this example demonstrates: 
I did have a grandma once who lives in Auckland, and her granddaughter was having her fourth birthday. And she came into the centre and she'd never ever been here before and she said to me "I feel like I know the place already because I've seen it through [the ePortfolio] (TI.1.1669).

This suggests that the ePortfolio is positively affecting teacher-parent relationships, resulting in a mix of both online and face-to-face conversations.

\subsubsection{Supporting children's learning}

This section draws from parents', wider whānau, and teachers' surveys, parents' and teachers' interviews, focus group interviews, and analysis of the exemplar and indepth learning stories. Data reported here focuses on participants' experiences and perspectives concerning children's learning being supported and extended, not whether learning actually took place.

The ePortfolio had potential to facilitate learning through one-way communication, for example if the parent read a learning story on the ePortfolio and decided to offer their child similar experiences at home and talk with them about it, or it could happen at the centre because of two-way communication via the ePortfolio through sharing comments or stories.

In the survey $35 \%(\mathrm{~N}=7)$ of parents identified similarities between the child's learning or experiences at home and at the centre. For example:

I often find my child will start doing a activity at home for example trying to throw the ball up high - the following week a story is loaded onto [the ePortfolio] and I realise that he has been participating and learning this activity at [the centre]! (PS.4.7).

These data were supported in the parent interviews, where three parents described how they provided further experiences at home, based on what was shared in the learning story. One parent identified that when the story was more focused on learning she was more likely to follow up on the interest or experience at home as she was more aware how it benefited her child. Two parents described how they posted 
stories on their child's ePortfolio where they had made links to a story a teacher had written and shown how they extended this learning at home. One example from a parent's interview is below:

So she was doing those little bead templates from Ikea with the tiny, tiny wee beads. And she's quite little still and she hasn't done a lot of really close, tiny fine motor skills stuff. And a teacher told us one day that she had spent a whole day doing an entire shape, or like an hour doing a shape. And we almost didn't believe it. She had one there, and we'd seen her come home with necklaces as well that had been threaded, but were dubious about who'd actually done it. But there were some photos they then put a story up on [the ePortfolio] that showed her sitting there and doing the beading, which was amazing cos we probably hadn't thought that she was capable of that yet. And after having seen it and talked to [the centre] about that, we've now got a few more tools for her that are a bit more sophisticated around fine work and things like that. So that was pretty exciting for us, as well as a proud parent moment (PI.4.936).

Three survey participants said they commented on the ePortfolio to engage with their child's learning, or to offer support or ideas to extend the experience. For example:

[To] exchange information with the teacher, so parents and teachers can work together to nurture some particular interest or encourage the child's learning and development in a particular area/subject (PS.6.13).

While there was considerable evidence in both the parent surveys and interviews of how learning and interests at the centre were followed up at home, it was less evident how teachers followed up on parents' and whānau comments or stories to influence the child's learning at the centre.

In-depth analysis of the four children's ePortfolios for threads of continuity supported this finding, with few stories having dialogue that shared information and supported or extended ongoing experiences or learning. 
Parents interviewed felt that there was limited follow up on the learning specified in the story. While teachers may have made suggestions there didn't seem to be further comments or stories to indicate that any follow up activity occurred:

Often there's not much of a back and forward on [the ePortfolio]. It's usually limited to the story and then a comment. There might sometimes be a short acknowledgement, but not very often will the story, the conversation continue in that way (PI.4.4173).

When asked about this in their focus group interview, two teachers reported it was easier to be specific when they were writing about something that had taken place, and there was a risk that if they were too specific looking forward that the child wouldn't follow up with what they had planned. Another teacher described how when she had non-contact time to write up what happened it seemed too late to write about the learning that was followed up as it had lost its timeliness. This suggests that what was included in the child's ePortfolio was only a small portion of what actually happened and may not give a full picture of children's ongoing learning. In the teacher survey two teachers described how they were trying to make their comments more focused on children's learning, for example:

I have been trying to improve by commenting on how I have seen the interest being extended for the child or if another teacher has written a story I have tried to make links about the interest or learning myself sometimes (TS.10.1).

This indicates that teachers were becoming more aware of including comments that better articulated children's learning.

\subsubsection{Online dialogue that supported learning}

When the thread of online dialogue was analysed in the exemplar stories it became apparent that some conversations were at a more surface level and others were more substantive. For example the following online conversation followed a story about an individual child challenging himself climbing up a rope net: 
Father: That's awesome, go Andy!

Grandparent: well done Andy

Aunty: Whaaaa hooooo

Terry (teacher): Yeah he sure is brave eh

Mother: That's really cool! He is learning so many awesome things at [the centre] - thank-you!

Terry (teacher): Yes I am sure that Andy will go from strength to strength.

Kia kaha!

Grandparent: Good skills little Man (ES.ind.5).

Much of this conversation is more about affirmation and appreciation, and adds little to the child's ongoing learning pathways. In contrast, the following online dialogue follows an individual story about a boy who is playing dramatically, pretending to catch a fish:

Grandparent: John, perhaps Daddy could take you fishing at the [City] pier when you come to stay with [Grandma] and Grandpa in January.

Mother: Yes he's been getting into 'fishing' quite a bit lately. Whenever we go to [the] park these days he will fashion himself a fishing rod out of a stick or piece of flax and we go fishing in the pond. Apparently I only catch small fish and he catches the big ones.

Terry (teacher): It's wonderful to hear how fishing has become a real interest for John. When I am outside next I'll be sure to set up a fishing activity.

Lisa (teacher): He's been really interested in 'Maui's magic jawbone'. We acted the Maui story out recently at mat time (story to come) and John has been using his own magic jawbone to do some fishing - just like Maui!

Terry (teacher): It's great to hear how John has been able to link his interest in fishing to this Maui myth (ES.ind.9).

This dialogue is more indicative of how the sharing of information by parents, family and teachers tells a deeper story of learning. This has more potential to influence the child's experiences both in the centre and at home, evidenced by the teacher and grandparent suggesting further experiences to offer John. 
These different levels of commenting were recognised by one of the teachers in their interview:

There's one grandparent that I think of that just says things like "good work" to their grandchild, which is nice. They've obviously appreciated it.

But I guess for me as a teacher, that doesn't then give me anywhere further to go. Some parents will comment and say, "oh they've been doing this at home" or "have you thought about doing this at the centre?" Those kind of comments I think help to then inform where you might go to next (TI.1.1036).

Twenty-four (61.5\%) exemplar stories had at least one comment that provided specific information about the child. The more these types of comments were included, the more substantive the conversation became.

In the survey teachers were asked how much the ePortfolio helped them communicate about children's learning. The table below shows that they felt communication between the home and centre via the ePortfolio was strengthened to a greater degree than communication more specifically about children's learning:

Table 4.4: Extent ePortfolios supported different types of communication

\begin{tabular}{|c|c|c|c|c|}
\hline $\begin{array}{c}\text { Teachers } \\
\text { How much do you think the } \\
\text { ePortfolios have helped }\end{array}$ & Occasionally & Quite a lot & A great deal \\
\hline $\begin{array}{c}\text { Strengthen the communication } \\
\text { between the centre and home }\end{array}$ & 0 & 0 & 3 & 4 \\
\hline $\begin{array}{c}\text { You communicate with parents } \\
\text { about children's learning }\end{array}$ & 0 & 1 & 4 & 2 \\
\hline $\begin{array}{c}\text { You to communicate with other } \\
\text { teachers about children's learning }\end{array}$ & 0 & 1 & 4 & 2 \\
\hline $\begin{array}{l}\text { You to communicate with wider } \\
\text { family about children's learning }\end{array}$ & 0 & 2 & & \\
\hline
\end{tabular}


This could indicate that some teachers view the ePortfolio as a general communication tool, rather than one that focuses on learning.

\subsubsection{Drawbacks of communicating through the ePortfolio}

The survey asked parents and wider whānau if they preferred to comment on individual or group stories, or had no preference. Fifty-eight percent $(\mathrm{N}=14)$ of parents and wider whānau had no preference to the type of story that they commented on in their child's ePortfolio, while $33 \%(\mathrm{~N}=8)$ preferred commenting on individual stories. During her interview, one parent said she was more careful about how she commented on group stories, being more likely to make general comments. Parents and teachers in the focus group interviews supported this view. Teachers described discussing this issue frequently at staff meetings, as they felt parents were less likely to comment on group stories, and that teachers were more inclined to make general comments on group stories to ensure they didn't single anyone out.

Another issue that arose in one parent interview was the potential for their comments to be misconstrued by the reader:

I think we're a little bit more cautious because you can't gauge the reaction at the other end. Whereas verbally you can, if you get the sense they haven't understood it in the way you mean, you can quickly follow up and correct the impression (PI.4.2451).

The benefit of the ePortfolio raising the level of communication for some families could also have negative implications if it influenced how teachers and parents responded, as these examples from a teacher and parent indicate:

.... And I think too the response that you get from the parents encourages you to want to write more stories and put more stories on there. When you've got those lovely comments back from parents, they're the - it's encouraging that you'll just want to put more stories up for their children (TI. 1.2360).

There are some teachers who post less, and whether it's because of that or not or whether that's just one factor, they are probably the teachers we have 
less of a relationship with or don't naturally go to, to ask about our child and what she might have done during the day (PI.4.3291).

This raises the question as to whether those parents who don't respond online, and those teachers who are less visible in the child's ePortfolio are disadvantaged in terms of the communication and relationship building.

This section demonstrates that the benefits from communicating via the ePortfolio platform were wide ranging. For parents, being informed about their child's experiences was very important, and the ePortfolio helped this. Face-to-face communication was also enhanced because of communication online. This in turn strengthened relationships between parents and teachers. Learning was at times extended at home because of what parents had read on the ePortfolio, though there was less evidence of on-going learning being supported at the centre when parents shared detailed information about their child. More general or affirmation type comments were less helpful to support learning. Drawbacks included the risk of being misunderstood limiting the depth of comments, and the potential for parents not engaging with the ePortfolio missing out on communication opportunities. The next section investigates how the ePortfolio platform and its associated tools influenced communication.

\subsection{Enablers and barriers of the ePortfolio platform}

The ePortfolio platform offered many tools that were not available with traditional hard-copy portfolios. Analysis of surveys and interviews revealed the ease of using the ePortfolio was significant for parents' engagement. For example, many parents noted having anytime access, or immediate notification of a new story or comment supported their involvement. Having access to photos and videos was also a highlight. These are described in further detail below:

\subsubsection{Ease of use}

In the survey and interviews it was clearly evident that the ePortfolio platform was regarded as easy to use, and this in turn influenced how participants used it. Having 
the ePortfolio accessible on the Internet meant that anyone invited into the ePortfolio could access it when it suited him or her. One example from a parent follows:

I am often in a rush to get to work in the mornings or pick up my elder child from after school care after the day care pick up which means I don't always have an opportunity to communicate about what has happened during the day. This mechanism [ePortfolio] enables me to communicate more easily with the teachers, and know what is happening at the centre (PS.4.13).

This ease of use, including receiving immediate notification of new stories was also apparent in the parent interviews, as one parent explained:

The fact that it's available on my iPhone and I can comment on it pretty much as soon as I get just an email notification that a new story's been [added] for Suzie. So it makes it really easy for me to interact with Suzie's teachers and see what she's been up to at daycare (PI.1.305).

This view was supported in the teachers' survey, where two teachers commented about how 24-hour accessibility supported parents' ease of use, for example:

I think the email alerts really help with this and that they have the ability to look at a time that suits them whether it is as soon as they get the alert at work or later in the evening at home, whereas with the paper profile books they would have to remember to look at them while they were at the centre or to take them home (TS.3.1).

One teacher also noted how the easy access enabled her to review previous stories and make links to current stories, whereas this was not possible with hard-copy portfolios if the book was at home.

While there was a range of tools available within the ePortfolio site, teachers and parents used these to varying degrees. For example in the survey $45 \%(\mathrm{~N}=9)$ of parents said they commented seldom or occasionally, and $50 \%(\mathrm{~N}=9)$ never added a story. Whilst all teachers interviewed described using the tag function to highlight the significant learning happening in the learning stories, two parents interviewed said 
they didn't find the learning tags useful, as the number of individual stories received didn't warrant a 'tag' keyword search.

Being able to use multi-modal communication such as text, photo, voice, and video all in one place was another feature that the ePortfolio provided. In the survey and interviews both parents and teachers noted the value of the photos and videos. One teacher described the importance of being able to add video to the children's stories:

I will often try if and where possible to get a video...because that adds a whole other element that a picture, even though they say a picture speaks a thousand words - a video can just totally show exactly how it was and exactly what was going on (TI.3.4998).

When analysing the comments from the exemplar stories $6 \%$ of parents' $(\mathrm{N}=5)$ and teachers' $(\mathrm{N}=5)$ comments and $12 \%(\mathrm{~N}=5)$ of wider whānau comments specifically referred to the photos or videos in the stories, suggesting these elements supported their engagement with the stories.

\subsubsection{Barriers created by the ePortfolio tools in regards to communication}

Several issues were identified that negatively influenced communication through the ePortfolio. In the parent interviews and focus group interview it was evident that the number of notification emails generated from group stories could be annoying to parents and wider whānau. While this function could be turned off it meant no notifications for the individual stories would be received either, which parents appreciated getting. Two participants said their children's grandparents had also been frustrated by these emails, with one grandparent asking to be removed from the ePortfolio as a result. Another issue brought up by two parents in their interview was receiving an email notification of a group story when their child wasn't included in the story.

\subsection{Content of communication evident through online comments}

This section reports findings on the content of online communication through the comments in children's ePortfolios, but does not take into account face-to-face 
conversations that may have happened alongside these online conversations. Data are drawn from the analysis of comments made by teachers, parents, and wider whānau in the exemplar stories, and the online surveys regarding respondents' reasons for commenting. One comment could be separated and coded into several different categories, though each section of comment was only coded to one category. An example of one comment that has been coded into three different categories is below:

Thanks Terry, a lovely story. The boys have spent the summer watching Steve play cricket on Sat mornings so maybe they have been itching to have a go themselves. Anyway we got locked out of the house five days ago and so I organised a cricket game in the garden and we discovered that Rick is a cracking bowler (and John an enthusiastic fielder). I'm sure they would love more T Ball games at [the Centre] when the weather permits.

Table 4.5: Categories coded from the example online comment

\begin{tabular}{|l|l|}
\hline Highlighted section & Category \\
\hline Light grey & Appreciation \\
\hline Dark grey & Giving further information \\
\hline No highlight & Suggestion for what next \\
\hline
\end{tabular}

Figure 4.1 presents the different categories of comments: 


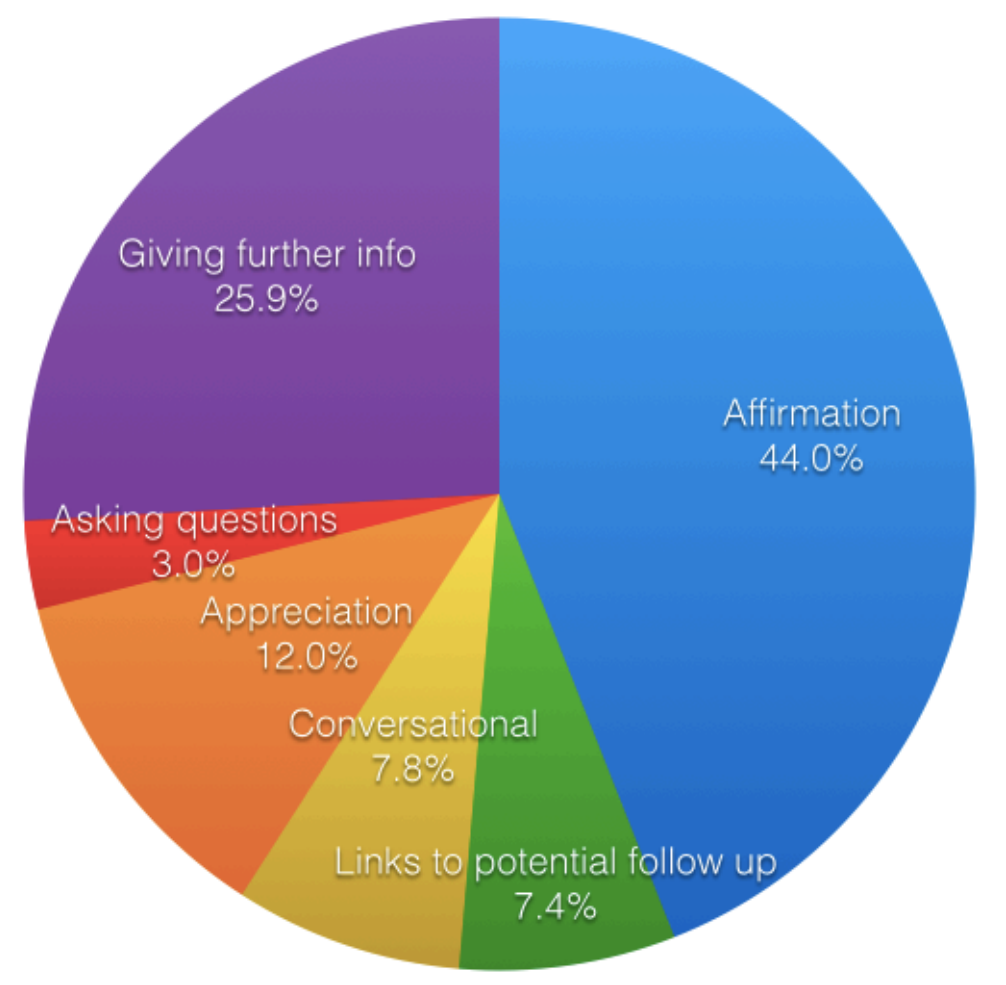

Figure 4.1: Types of comments made by participants

Table 4.6 presents data on the number of comments in each of the six categories made by the different groups of users - teachers, parents, and wider whānau:

Table 4.6: Types of comments made by teachers, parents, and wider whānau

\begin{tabular}{|c|c|c|c|c|}
\hline Types of comments & Teachers & Parents & $\begin{array}{c}\text { Wider } \\
\text { whānau }\end{array}$ & $\begin{array}{c}\text { Percentage of all } \\
\text { comments }\end{array}$ \\
\hline Affirming experience / child & 39 & 39 & 36 & 114 \\
$(35.5 \%)$ & $(41 \%)$ & $(74 \%)$ & 5 \\
\hline Giving further information & 28 & 34 & $(10 \%)$ & $(25.9 \%)$ \\
\hline Appreciation & $(25.5 \%)$ & $(33 \%)$ & 2 & 31 \\
& 15 & 14 & $(12 \%)$ \\
\hline Conversational & $(14 \%)$ & $(13 \%)$ & 2 & 20 \\
& $(11 \%)$ & $(6 \%)$ & $(5 \%)$ & $(7.75 \%)$ \\
\hline Links to potential follow up & 10 & 6 & 3 & 19 \\
& $(9 \%)$ & $(6 \%)$ & $(7 \%)$ & $(7.35 \%)$ \\
\hline Asking a question & 6 & 1 & 1 & 8 \\
& $(5 \%)$ & $(1 \%)$ & $(2 \%)$ & $(3 \%)$ \\
\hline Total & 110 & 100 & 49 & 259 \\
& $(100 \%)$ & $(100 \%)$ & $(100 \%)$ & $(100 \%)$ \\
\hline
\end{tabular}


The data in Figure 4.1 and Table 4.6 show that there were six categories of comments. The most frequently occurring category was affirmation $(\mathrm{N}=114,44 \%)$, followed by giving further information $(\mathrm{N}=27,25.9 \%)$, and appreciation $(\mathrm{N}=31,12 \%)$. The remaining categories occurred less frequently: conversational $(\mathrm{N}=20,7.75 \%)$, links to potential follow up $(\mathrm{N}=19,7.35 \%)$, and asking a question $(\mathrm{N}=8,3 \%)$. Each category is explained in more detail below, with examples to illustrate.

\subsubsection{Affirmation}

The data from the learning story comments showed that affirmation was the most frequent type of comment $(44 \%, \mathrm{~N}=114)$, and that wider whānau used this type of commenting most often $(\mathrm{N}=36,74 \%)$. Comments in this category included affirming the child in the story, the experience described in the story, or the comment made by another person.

Table 4.7: Examples of different types of affirming comments.

\begin{tabular}{|l|l|}
\hline Affirming: & Comments: \\
\hline The child & $\begin{array}{l}\text { Nice to see the boys enjoying the computer } \\
\text { together }\end{array}$ \\
\hline The experience & $\begin{array}{l}\text { Love the dance moves! Having a long day so } \\
\text { had to log on and view this one again :) }\end{array}$ \\
\hline The previous comment & $\begin{array}{l}\text { Kia ora Rex, wow that is so interesting to } \\
\text { hear }\end{array}$ \\
\hline
\end{tabular}

There was a nearly equal spread of comments between affirming the experience and affirming the child by teachers, parents, and wider whānau. Only teachers affirmed comments made by others, with $16 \%(\mathrm{~N}=6)$ of their comments in this sub-category.

In the survey the most frequent reason for wider whānau and third most frequent reason for parents to comment was to give affirmation. Examples of reasons for commenting that relate to affirmation are below:

As I am on the other side of the world, my grandson can see that I am in touch with what he is doing and that I am interested and very proud of him (WWS.6.1). 
I also comment if it is a fantastic story, or I can see he is taking part in something exciting. I try not to make general comments (ones you would make on a facebook post) more comments to celebrate his achievements... (PS.6.8).

Interestingly, while no teachers in the survey noted giving affirmation as a reason to comment, this was the most frequent type of comment teachers made in the exemplar stories $(35.9 \%, \mathrm{~N}=39)$.

\subsubsection{Giving further information}

Giving further information was the second most frequent type of comment made $(\mathrm{N}=67,25.9 \%)$. Many comments shared specific information about the child related to the learning story, with $71 \%(\mathrm{~N}=24)$ of parents' comments and $57 \%(\mathrm{~N}=16)$ of teachers' comments being in this sub-category.

The following teachers' comments are examples of sharing specific information about a child. The story was about a child who had been persisting with placing tiny beads onto a heart shaped frame, but the beads kept getting knocked off for various reasons:

Alwin made another creation today. She worked really hard at it for almost an hour and was thrilled to see it ironed and stick together.

Then another teacher commented:

The first time she made it, she excitedly held it up to show me! Millions of beads all over the floor and a very sad face! All I needed to say was "I'm sure you can remake that in no time Alwin" and she sat up at the kai table remaking her heart (through a few tears) (ES.ind.11). 
An example of a specific comment from a parent was in a story about two children developing a close friendship:

We showed Liz these pictures at home, and she was very keen to keep looking at them, and often asked to see them again; she even started describing what was happening in detail (Liz and Colin going down slide!) when I came to pick her up last week (ES.group.10).

Other types of information shared included more general statements about the child $(\mathrm{N}=13)$ or the experience $(\mathrm{N}=6)$, general information on the topic within the story $(\mathrm{N}=4)$, or sharing their own experiences around the story topic $(\mathrm{N}=2)$ :

Table 4.8: Examples and frequency of types of information shared

\begin{tabular}{|c|c|c|c|c|}
\hline \multirow{2}{*}{$\begin{array}{l}\text { Types of information } \\
\text { shared: }\end{array}$} & \multicolumn{3}{|c|}{ Frequency of comments } & \multirow[t]{2}{*}{ Example of Comment: } \\
\hline & Teachers & Parents & $\begin{array}{l}\text { Wider } \\
\text { whānau }\end{array}$ & \\
\hline $\begin{array}{l}\text { General information about } \\
\text { the child }\end{array}$ & 5 & 6 & 2 & $\begin{array}{lrr}\text { He loves jumping off } \\
\text { everything! }\end{array}$ \\
\hline $\begin{array}{c}\text { General information about } \\
\text { the experience }\end{array}$ & 3 & 3 & 0 & $\begin{array}{l}\text { It sure was yummy, the } \\
\text { children had [the walnut loaf] } \\
\text { for afternoon kai and the } \\
\text { teachers along with some } \\
\text { parents polished off the rest. }\end{array}$ \\
\hline $\begin{array}{c}\text { General information on the } \\
\text { topic }\end{array}$ & 3 & 1 & 0 & $\begin{array}{l}\text { A parent explains the sewage } \\
\text { system on a ship in relation to } \\
\text { a story: It gets processed in } \\
\text { the holding tanks by bugs } \\
\text { until it is clean water and then } \\
\text { goes out into the sea. }\end{array}$ \\
\hline Sharing own experience & 1 & 0 & 1 & $\begin{array}{l}\text { I remember baking with my } \\
\text { mum when I was a child. Its a } \\
\text { wonderfully homely activity } \\
\text { with the added bonus of } \\
\text { introducing children to some } \\
\text { math }\end{array}$ \\
\hline
\end{tabular}


Giving information was the second most frequent reason $(\mathrm{N}=5,20 \%)$ parents gave in the survey for commenting on stories. This was often because when they recognised similar learning or interests happening at home and the centre they wanted to share this with teachers. All four parents interviewed noted the importance of sharing information to give insights into what their children did at home. One parent described how providing more information showed that parents valued what teachers were doing:

It's also good for teachers to get feedback. So I made sure that Terry knew what Amy was doing at home with the puppets, because then he would know that there was value in what he was doing with the children during the day (PI.2.1202).

This suggests that parents may also make these types of comments as a way of showing appreciation of teachers.

Teachers felt that ePortfolios made it easier for parents to share information from home, especially in relation to what was happening at the centre. For example:

[The ePortfolio] has definitely made it easier for the parents to communicate their life outside the centre as they can add stories at a time that suits them. This has not replaced the parents telling us stories in person but for some families it has helped support these stories (TS.3.1).

Several teachers also described how they would comment on other teachers' stories to give more insight into children's experiences.

\subsubsection{Appreciation}

The data showed appreciation comments were the third most frequently occurring type of comments used $(12 \%, \mathrm{~N}=31)$. These types of comments involved thanking in some way. Parents and wider whānau thanked teachers for writing the story or supporting their child, while teachers thanked parents for their comments or information they had shared, and thanked other teachers for providing the experience. 
For example one teacher had written a group story about a teacher-organised experience called 'clubs' which she had taken for another teacher that day.

Fifty percent $(\mathrm{N}=7)$ of parents' comments and $40 \%(\mathrm{~N}=6)$ of teachers' comments in this category started with the word 'thanks', perhaps suggesting this type of comment is a sentence starter. This was supported by data from the teacher focus group interview where one teacher described thanking as an "almost automatic response". Another teacher said how difficult it was to respond to a comment that only had a 'thank-you' type focus. Further analysis showed that $87 \%$ of appreciation comments were part of a longer comment that included other categories, indicating that people usually did elaborate beyond "thank-you".

The most frequent reason parents gave for commenting was to show appreciation. There were different aspects of appreciation, including the work teachers did with their child, and teachers sharing more about themselves. For example:

I love being kept up-to-date and appreciate the teachers taking the time to post the stories. Commenting on stories is the least I can do (PS.6.16).

Two parents interviewed also described the importance of acknowledging the teachers and the work they did. This acknowledgement was received positively by teachers, where one teacher said comments encouraged her to write more, and another described:

It's great, cos she [the grandparent] leaves really long comments and it makes you feel, it's quite rewarding, because - that you're able to touch someone out that far [overseas] and help them to see what their grandchildren are doing (TI.2.1222).

Giving appreciation also featured in the teachers' survey data where four teachers noted this as a reason to comment. For example:

If a parent has made the effort to share a story I like to comment and acknowledge their input (TS.5.3). 


\subsubsection{Links to potential follow up}

The category links to potential follow up accounted for $7 \%(\mathrm{~N}=19)$ of comments. These were comments that referred to some type of future follow up to the experience described in the story. Teachers $(9 \%, \mathrm{~N}=10)$ were slightly more likely to make this type of comment than parents, $(6 \%, \mathrm{~N}=6)$. Of the ten comments made by teachers in this category, four were quite general in nature:

\footnotetext{
We are hoping to take some more trips to [another centre] soon (ES.group.20).
}

I look forward to more organised chaos (ES.group.21).

Two were more specific, for example:

Next time I'm outside and its good weather I'll get out the softball equipment so they can play some more (ES.group.11).

Another two invited the parent or child to participate in some way, for example:

Luke can bring his lunchbox in each day for sure (ES.ind.13).

More specific comments for potential follow-up were mostly made on individual children's ePortfolio stories. Because only the exemplar stories were analysed, data wasn't available to ascertain if these comments were followed up.

\subsubsection{Conversational}

Conversational comments accounted for $7.75 \%(\mathrm{~N}=20)$ of the comments. These were comments that were generally chatty, involved humour, or were unrelated to the story. Below is an example of a conversational comment from a parent:

Parent: With a bit more practice perhaps I can get John to put my makeup on in the morning (ES.group.15). 


\subsubsection{Asking a question}

Asking a question was the least frequently occurring category across all groups, accounting for only $3 \%(\mathrm{~N}=8)$ of comments. Across all the exemplar stories only one parent and one wider whānau asked a question. The example below was a group story about a teacher-organised activity making smoothies in a blender. A parent commented that her son had made his own recipe and the teacher responded:

Oh what does he like to put in it? (ES.group.16).

\subsection{Framework of effective two-way communication used in this study}

Chapter two presented a theoretical framework for effective two-way communication using a hypothesis from Bronfenbrenner (1979). Using that framework, this section uses the three concepts of trust, a balance of power, and goal consensus between parents and teachers to examine whether these concepts were evident in the data collected. This section draws data from the parents' and teachers' surveys, the parents' and teachers' interviews, and the focus group interviews.

\section{$\underline{4.5 .1 \text { Trust }}$}

The survey asked parents and teachers to think of their own experiences in relation to each other, then rate each of ten statements using a Likert five point rating scale (see appendix 1, question 18) ranging from strongly disagree to strongly agree. These statements were classified into the five different elements of relational trust as described by Goddard, et al. (2001) (refer section 2.1.2). For example, a statement that related to benevolence was parents/teachers are friendly and approachable. 
Table 4.9: Measures of parents' and teachers' trust in each other

\begin{tabular}{|c|c|c|c|c|c|c|c|}
\hline $\begin{array}{c}\text { Elements of } \\
\text { trust }\end{array}$ & Group & 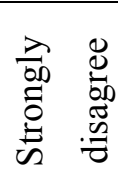 & 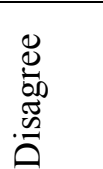 & $\begin{array}{l}\bar{\pi} \\
\stackrel{\vec{E}}{0} \\
\text { Z }\end{array}$ & 造 & 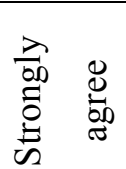 & 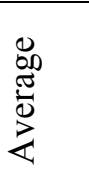 \\
\hline \multirow[t]{2}{*}{ Benevolence } & parents & $0 \%$ & $0 \%$ & 0 & $24 \%$ & $76 \%$ & 4.76 \\
\hline & teachers & $0 \%$ & $0 \%$ & $14 \%$ & $57 \%$ & $36 \%$ & 4.29 \\
\hline \multirow[t]{2}{*}{ Honesty } & parents & $0 \%$ & $0 \%$ & $6 \%$ & $47 \%$ & $47 \%$ & 4.41 \\
\hline & teachers & $0 \%$ & $0 \%$ & $7 \%$ & $64 \%$ & $29 \%$ & 4.29 \\
\hline \multirow[t]{2}{*}{ Reliability } & parents & $0 \%$ & $0 \%$ & $9 \%$ & $50 \%$ & $41 \%$ & 4.41 \\
\hline & teachers & $0 \%$ & $0 \%$ & $7 \%$ & $79 \%$ & $14 \%$ & 4.07 \\
\hline \multirow[t]{2}{*}{ Competence } & parents & $0 \%$ & $0 \%$ & $6 \%$ & $38 \%$ & $56 \%$ & 4.36 \\
\hline & teachers & $0 \%$ & $0 \%$ & $14 \%$ & $43 \%$ & $43 \%$ & 4.29 \\
\hline \multirow[t]{2}{*}{ Openness } & parents & $0 \%$ & $0 \%$ & $6 \%$ & $67 \%$ & $27 \%$ & 4.21 \\
\hline & teachers & $0 \%$ & $14 \%$ & 0 & $71 \%$ & $14 \%$ & 3.86 \\
\hline
\end{tabular}

Table 4.9 presents data on parent' and teachers' perspectives on trust. Whilst all measures of relational trust between parents and teachers were rated highly, parents rated each trust category slightly higher than teachers when an average was applied to the scores (when, strongly disagree $=1$, and strongly agree $=5$ ). Benevolence (friendliness and caring) was rated the highest measure of trust for parents, whilst openness was rated the lowest type of trust for both groups. Parents' and teachers' most frequent reason for making a comment on the ePortfolio was to show their appreciation, and this could be linked to high levels of benevolence.

When the responses from the survey regarding how often parents commented were compared to levels of trust using cross tabulation, trust levels did not increase with the frequency of comments that parents self-reported in the survey. Several explanations may be possible, for example, parents who do not comment in an online environment may converse face-to-face instead and build trust in that way. Perhaps those parents 
who comment least trust the teachers the most, and therefore have less need or desire to comment. Furthermore, this is a very small sample, so low numbers of participants, especially of teachers, can result in quite large apparent percentage differences just by one person shifting their view.

When teachers in the focus group interview were asked about the lower rating of openness by parents, one teacher responded that before openness was generally possible the other types of trust needed to be displayed, while another teacher suggested that a professional teacher needed to set boundaries and keep a work-life balance which could affect the degree of openness they were prepared to have with parents. Parents in the focus group interview were surprised by the openness rating from teachers; one parent said that perhaps if parents only approached one teacher, other teachers could regard them as less open. They also felt that affirmation type comments made in the ePortfolios could link to the high level of benevolence. The positive affect ePortfolios had on relationships that was described in section 4.1.1.3 could also be linked to high levels of benevolence.

In regards to openness, parents readily shared their home life through comments and stories. Parents also appreciated it when teachers shared about their own holidays on the ePortfolio, as they felt they got to know them better, with one parent saying it helped to build a sense of family.

The trust element of competence was evident when the data from the teachers' and parents' surveys and interviews were analysed. There were many positive comments from parents in the surveys and interviews about teachers' competence:

Sometimes I quite often think wow, especially when they've actually quoted the children. I actually always think wow, how do they manage to get all that down. Cos I know what it's like working in there and what you're juggling and that there's a lot going on (PI.2.5471).

Postings on "club" [planned on-going small group experiences] activities were done really well by staff (PS.4.4). 
Though some parents interviewed felt that teachers didn't always make the learning explicit:

So some teachers definitely do write with more eye to things like the curriculum. So they'll be more explicit that this is a curriculum related piece of learning. And others will be that it's a more fun activity or something we all did (PI.3.6314.).

A lot of it is based on activity and what they've been up to, and then relating that back to Te Whāriki. But I can't really tell the difference between descriptive stories about what they've been learning versus what activity they've been doing. So I don't know - maybe I just can't see the connection between activity versus learning (PI.1.1714).

Another parent felt that more experienced teachers were better at highlighting learning rather than just focusing on the fun aspect of the experience, whilst a third parent noted that teachers could make more links to previous stories to show progress over time, and show how learning was followed up in current stories. This issue was explored further when analysing the exemplar stories: $54 \%$ of the group and individual stories analysed were found to have some link to a previous story, interest, or experience. These exemplar stories were only a very small portion of the total stories written, so these percentages may not be indicative across all stories. On a more technical level, all parents interviewed noted errors in spelling and grammar in the learning stories, which some found concerning.

\subsubsection{Balance of power}

This section focuses on the balance of power between teachers and parents, the second concept of Bronfenbrenner's two-way communication. I have drawn on Porter's (2008) power framework, which provided deductive categories to analyse the qualitative data. The power continuum she described used headings of professional driven, family orientated, family centred, and family driven. In the category professional driven the power was held by the educator or professional, where their specialist knowledge was considered the only information relevant, whereas at the other end of the continuum, family driven positioned the power with the family, where parents were seen as the professionals employers. Each of the four categories had key 
characteristics relating to communication and relationships that were used for the deductive analysis (see section 2.1.1). Data analysis revealed family-centred practices were the most frequently occurring category. Parents advocated for their children by sharing information with the centre about the child's home life and interests, through both commenting and adding stories on line. In this way parents took opportunities to influence their child's experiences whilst at the centre, as in this example from a parent interview:

It must have been around three, three and a half. Her best friend left to go to kindy. She had a really hard time at that time re-making friends and she was just struggling with it. And we used [the ePortfolio] as a way to bring some things to [the centre] from home that I didn't want her to actually bring. So we had things like some fairies out from the toy library. And she really wanted to bring them to [the centre] ... so we took photos of her with them and we wrote our own story so that she could share her story at mat time of the fairies and things to help bring some things from home to [the centre]...

Interviewer: ... What difference has that made to your child having this sort of interaction between home and doing it online?

Louise: Well I wouldn't have done it in a book, I think would be the main thing. So I wouldn't have done it if it wasn't online...there wasn't a way before for me to do some - that wasn't difficult, there was a way before. I could have printed out pictures and stuck them on a bit of paper and put them in. I could have done that - I wouldn't have...

So we had fairies at home and we dressed up like a fairy and had the fairy story and then there was discussion about fairies at [the centre] and then they bought fairies for [the centre]. So which really came from that whole thing. And I think because I had shown the pictures of the fairies, they were able to be much more precise about what the big interest was (PI.3.3871).

Porter (2008) described sharing information as an indicator of family centred practice when it occurred in a way that enabled power to be shared so parents and teachers had equal status. When teachers were asked about their reasons for communicating with parents, all teachers noted the importance of finding out about families' home life so they could better support children's learning. Some went further, describing the 
importance of building a relationship and supporting continuity between home and the centre. Interestingly, when teachers were asked about why they commented they were more focused on acknowledging parents. This suggests that teachers saw commenting on stories as a way to build relationships with parents rather than to support children's on-going learning.

Language used by professionals was also recognised as a way of having power over others, partcularly when technical or academic language was used (Hughes \& MacNaughton, 2011). The analysis of exemplar stories indicated that the language used by teachers in both stories and comments was positive and mostly conversational, with minimal academic language used.

\section{$\underline{4.5 .3 \text { Goal consensus }}$}

Goal consensus was the third concept from Bronfenbrenner's two-way communication model (see section 2.13). In NZ ECE services the notion of shared aspirations for children's learning is recognised, and has been used as a construct for understanding goal consensus within the context of this study.

The teacher and parent surveys included a question asking how effectively the ePortfolio helped parents share their aspirations for their child while at the centre. The parent survey also included a question regarding how teachers responded to their aspirations.

Table 4.10: Parents aspirations for their children shared with teachers

\begin{tabular}{|l|l|l|l|l|l|}
\hline Respondent & \multicolumn{1}{|c|}{$\begin{array}{l}\text { How the ePortfolio: } \\
\text { Teachers }\end{array}$} & $\begin{array}{c}\text { Not at } \\
\text { all }\end{array}$ & $\begin{array}{l}\text { Occasion- } \\
\text { ally }\end{array}$ & $\begin{array}{l}\text { Quite a } \\
\text { lot }\end{array}$ & $\begin{array}{c}\text { A great } \\
\text { deal }\end{array}$ \\
\hline Parents & $\begin{array}{l}\text { Helps parent to share their } \\
\text { aspirations for their child }\end{array}$ & 0 & 4 & 2 & 1 \\
$(57 \%)$ & $(29 \%)$ & $(14 \%)$ \\
\hline Parents & $\begin{array}{l}\text { Helps teachers to respond to } \\
\text { parents aspirations for their } \\
\text { child }\end{array}$ & $\begin{array}{l}2 \\
(10 \%)\end{array}$ & $\begin{array}{l}10 \\
(50 \%)\end{array}$ & $\begin{array}{l}(50 \%) \\
(30 \%)\end{array}$ & $\begin{array}{l}(35 \%) \\
(10 \%)\end{array}$ \\
\hline
\end{tabular}


Table 4.10 presents these data and indicates that ePortfolios are used to varying degrees to share parents' aspirations for their child, with the most frequent response being occasionally. When asked to give examples, no parents and only one teacher noted parents' aspirations in the follow up survey question:

I've put a little for parents to say their aspirations at the centre as for a lot of parents I'm not sure that they use [the ePortfolio] necessarily as a way to share their aspirations....this probably is more likely on a whole to happen in person at occasions such as parent teacher interviews and regular informal chats (TS.3.1).

In the interview one parent noted she would not use the ePortfolio to share her aspirations for her child, especially if these could be considered challenging. She felt a face-to-face conversation would be more appropriate for this type of discussion. This approach was also evident in a teacher interview where a teacher described a conversation with a parent about risk taking, where the teacher had been concerned that the parent may not agree with this type of play, so talked to her face-to-face before posting the story.

When analysing the exemplar learning stories, some affirmation comments revealed implicit sharing of aspirations. For example:

Liz seems to have a real curiosity about all new and different things which is vital to her learning and development (ES.ind.5).

I am so happy seeing Luke interacting with the other boys (ES.group.21).

These comments indicate that the writers may value curiosity and friendships respectively, and thus be interpreted as aspirations for the child. Twenty-three per cent $(\mathrm{N}=10)$ of parents' affirmation comments and $13 \%(\mathrm{~N}=5)$ of teachers' comments were of this nature.

In the interviews parents were asked if learning they valued was evident in the stories written by teachers. Three parents felt teachers could strengthen this aspect of learning stories. Two parents wanted to be able to compare their child's progress; one 
parent was interested in comparing her child's skill development over time, and one felt learning stories were an ineffective tool to judge how well her child was progressing.

Using Bronfenbrenner's framework has given another lens to analyse the data. Content of the online comments can be linked to all three elements: affirming and appreciation comments supported the trust element of benevolence, whilst providing information and identifying potential on-going learning supported shared power and goal consensus. Comments that provided information linked to children's on-going learning were less frequent, and as a result, trust elements of competence and openness may have been reduced.

\subsection{Summary}

This chapter has presented the findings using the key themes emerging through the data analysis. EPortfolios have facilitated both online and face-to-face communication for many parents, teachers and wider whānau. Participants chose to communicate for different reasons, thus affecting the content of their communication. The ease of use of the online tools has been a major factor in this enhanced communication. The online communication strengthened teacher-parent relationships, and facilitated on-going learning at home and to a lesser extent at the centre. In regards to Bronfenbrenner's communication framework, there were high levels of trust between parents and teachers, though levels of trust didn't relate to frequency of commenting. There was evidence of a shared power model in regards to communication and relationships. Whilst goal consensus was less evident there were implicit examples of this happening. The next chapter discusses these themes in more depth, referring to the literature review in chapter two. 


\section{CHAPTER 5: DISCUSSION}

In this chapter the results of the study are discussed in relation to the research questions. These were:

1. How do ePortfolios facilitate communication between families and teachers in an EC centre?

2. What type of communication is fostered through the use of ePortfolios in an EC centre?

3. What impact does communication through the use of ePortfolios have on teacher-parent relationships and children's on-going learning?

4. How do teachers' values and beliefs about communicating with families influence communication through ePortfolios in an EC centre?

From the inductive analysis of data it became evident there was minimal data that addressed question four. Whilst questions around values and beliefs were included in the teacher surveys and teacher and parent interviews they elicited limited data. Therefore it was decided not to include this question in the discussion.

I then discuss Bronfenbrenner's theoretical framework in which he argues that a balance of power, enhanced trust, and goal consensus are needed in order to support two-way communication to achieve positive outcomes for the developing person. This is followed by a discussion of limitations of the research, and possible directions for future research. I conclude with implications and issues that have arisen from this study.

\subsection{How ePortfolios facilitate communication between families and teachers}

The ePortfolio platform provided an avenue for most participants to communicate, which often led to face-to-face conversations. Families chose to participate in different levels of communication that ranged from one-way communication to twoway communication, where families responded to teachers' stories or added their own, helping to give a wider perspective of their child's experiences and learning. These two levels of communication are discussed in more depth below, followed by a discussion of the various tools afforded by the ePortfolio that facilitated communication. 


\subsubsection{One-way communication}

The first level of communication evident was one-way communication. This was where parents and wider whānau were informed by teachers via the ePortfolio about their child's experiences and learning at the centre. The importance to families of being informed about their child was a key finding, and concurs with Goodman's (2013b) findings. Through being informed, families were then able to make links to what the child was doing at home, sometimes extending the experience described in the teacher's story.

This finding is reflected in results from other research, where it was important for parents to be informed about their child's daily experiences when they were unable to be with them (Bernhard et al., 1998; Elliot, 2003; Reedy \& McGrath, 2010). Information teachers communicated via the ePortfolio in this study addressed this need for most parents. This suggests that some parents valued the ePortfolio as a tool for keeping them informed, rather than a two-way communication tool. This view supports Ghazvini and Readdick's (1994) research, where most parents felt that oneway communication was more important than two-way communication.

\subsubsection{Two-way communication}

The second level of communication was two-way, where parents responded to the teachers' stories via the ePortfolio platform commenting tool or added their own story. Almost all participating parents in the study commented on a story at least once (96.5\%), and 44\% $(\mathrm{N}=12)$ added their own story at least once, showing a high level of engagement, especially when compared to Meade et al.'s (2012) research where 44\% of parents in the case studies had contributed to the hard-copy portfolio at least once. This suggests the ePortfolio platform could encourage a higher response rate from parents than has been evident with traditional paper-based portfolios.

Hatherly et al. (2009) and Goodman (2013b) found when parents felt more informed about daily happenings through their child's ePortfolio they had increased confidence to talk directly with teachers. Three-quarters of parents in this study felt the ePortfolio had helped them communicate with teachers about their children's lives outside the centre. This response rate is high compared with Goodman's (2013a) study, where $42.8 \%$ of parents asked the same question felt that ePortfolios helped them 
communicate. There are a number of possible explanations, including that the centre in this study was in a high socio-economic area so participants may have had greater access to, and been more confident with ICT; staff from the case study centre were all qualified; or different ePortfolio platforms may have been used.

\subsection{3 ePortfolio tools that facilitate communication}

Having twenty-four hour access to the ePortfolio via the Internet and receiving email alerts when a new story was added meant participants were kept informed of new stories, and could view and use the ePortfolio when it suited them. It also gave an opportunity for parents and wider whānau to easily give feedback if they wanted through commenting or adding their own story. The immediacy provided by the ePortfolio was also reported in Hatherly et al.'s (2009) research, which found greater collaboration between teachers and families. The asynchronistic element of the commenting tool meant that teachers and parents did not need to be physically available at the same time, thus alleviating many of the issues in regards to finding a convenient time and place to talk for both teachers and parents as described by MacNaughton (2004), NZCER (2007), and McGrath (2007).

\subsection{Types of communication fostered}

Various types of communication were fostered through the ePortfolio, including the content of comments and the depth of online dialogue created by the thread of comments attached to each story. These are discussed below:

\subsubsection{Content of communication}

Affirmation was the most frequent type of comments made by parents, teachers, and whānau. This differs from Meade's (2012) research where most parents' feedback in the hard-copy portfolio book focused on describing the child's interests at home. This may indicate that commenting online was viewed as informal conversation, much the same as using Facebook, so could be seen differently than writing in a hard copy portfolio. This informal nature of conversations was seen as an important way for parents to build rapport and trust with teachers in Martin's (2006) and Reedy and McGrath's (2010) studies. While these related to face-to-face conversations, parallels can be seen in regards to the informality of online comments in this study. 


\subsubsection{Surface versus substantive dialogue}

Ten percent of ePortfolio stories received five or more comments. While this was a significant quantity of comments, it didn't always ensure a depth or substance of conversation. Substantive dialogue was more likely when specific information was shared about the child. Sharing information was the second most frequent type of comment $(25.9 \%)$, with $61.5 \%$ of the exemplar stories having at least one of these comments. This appears higher than results reported in Meade et al.'s. study (2012) where only two of the ten services in their case study managed to set up substantive dialogue with "one or two" (p.57) parents in the hard-copy portfolio on at least one occasion. However they did note dialogue occurred more often via email when this approach was used. This could suggest that even with a high level of affirmation commentary, substantive dialogue is more likely to happen online than in a paperbased format. Substantive conversations are discussed further in the next section in regards to children's on-going learning.

\subsection{Impact of communication on relationships and on-going learning}

All participating parents and teachers felt the ePortfolio helped strengthen their relationships with each other. Teachers described parents contributing more to the curriculum, and having more conversations both online and face-to-face as examples of these growing relationships. This finding is supported by Hatherly (2010), who found that conversations with teachers happened more readily when parents were using ePortfolios, and this led to stronger relationships.

In Martin's (2006) study, parents frequently cited the need for increased two-way communication, and a greater flow of information to improve the partnership relationship. The ePortfolio has offered another avenue for parents to give feedback, with the ease with which this can be done on the ePortfolio platform appearing to increase the amount of feedback.

While the quantity of online communication was significant and helped to build relationships, this didn't always mean that the content was useful to build on children's learning in the centre. As in Elliot's (2003) and Meade et al.'s (2012) 
research some parents reported a lack of detail about the learning in their child's stories.

From the interviews it became apparent that some parents and teachers preferred to receive comments that gave more information about children's experiences, as these were both easier to respond to and helped to support the child's learning. Despite this preference, affirmation type comments were more frequent (44\%) than those that shared information (25.9\%). This suggests that comments that link to children's ongoing experiences and learning were more difficult to make than affirmation comments, or that participants didn't appreciate how these types of comments could influence children's ongoing experiences and learning. Both Hatherly (2010) and Cherrington et al. (2009) highlighted the importance of making learning visible, rather then describing the experience or simply providing photograhic evidence. Sharing specific information about children went one step in this direction, but generally there was little evidence that online dialogue supported on-going learning by itself.

The case study completed by Rotorua Girls High School Childcare Trust (2009) noted that comments participants made on the ePortfolio became more focused on learning as time went on. This indicates that the content of comments develops over time as people engage with the ePortfolio, and could explain why some parents and teachers made reference to preferring comments more focused on sharing information.

\subsection{Key theoretical concepts of two-way communication}

The three concepts of two-way communication drawn from Bronfenbrenner's hypothesis - enhanced trust, balance of power, and consensus of goals - were all evident in the study, though some aspects were more evident than others.

According to Bronfenbrenner (1979) enhanced trust was a key element in developing two-way communication. The five elements of trust put forward by Goddard et al. (2001) (see section 2.1.2) between teachers and parents were investigated in this study. All five elements rated highly, especially in regards to friendliness and caring (benevolence), highlighting the enhanced relationships and communication the ePortfolio supported. The high incidence of appreciation-type comments may link to what Robinson et al. (2009) refer to as personal regard, closely related to 
benevolence. The frequent positive dialogue evident in much of the exemplar stories also corresponds with what Adams and Christensen (2000) reported in their research, where this type of dialogue helped to build trust.

Parents rated all trust categories more highly than teachers, which concurs with Adams and Christenson's (2000) research. Parents rated openness less present than other trust categories, which was also found in Janssen et al. (2012) study. To further develop trusting relationships both parents and teachers could consider how they may strengthen openness with each other. For example, how much information they are prepared to share about themselves and the child, and what information would be most useful to enhance the child's learning.

When the quantitative data in relation to measuring trust was cross tabulated with parents who classified themselves as frequent commenters, the more frequent commenters did not have higher levels of trust in teachers. This contrasts with assertions in the literature that trust was increased through communication (Adams \& Christenson, 1998; Swick, 2003) perhaps indicating that online communication effects trust differently than face-to-face communication, which other research was based on.

When different power sharing models (e.g., Dunst, et al., 1991; Dunst, 2002; Osher \& Osher, 2002; Porter, 2008) were considered in regards to communication, models of shared power was evident in the ePortfolio comments in the case study centre. For example, using Porter's (2008) continuum of parent-teacher relationship styles, online comments of affirmation and appreciation were located in the 'family-centred' category, where "communication aims to build a relationship and empower parent participation" (p.10). However more information about the centre and teaching practices is needed to apply the continuum to power sharing beyond online communication.

Another way of viewing power concerns whose knowledge was privileged. Teachers' informal language used in the ePortfolio may have helped to empower parents to communicate. Hughes and MacNaughton (2011) support this as the use of more technical language by teachers could privilege their knowledge over parents' knowledge. Hattie (2009) also described how parents' lack of understanding of teachers' language in the school sector meant they were less able to contribute. 
Shared power is evident when parents are able to advocate for their child when discussing their child with teachers (Osher \& Osher, 2002). By providing information about their child's interests and experiences at home, parents in this study were able to give teachers a broader understanding of their child. That at times affected how teachers were able to respond. This differs from Martin's (2006) research, where fulltime working parents were unable to advocate for their child due to the unavailability of avenues to have these types of conversations with teachers.

This sharing of information through online commenting also related to goal consensus, where shared understandings were sometimes developed through substantive dialogue (see section 5.2.2). At times affirmation comments also intimated values of the writer. This process of developing shared understandings is supported by Loveridge (2002) who points out that documentation is the starting point for dialogue, that assists in building shared understandings. Stonehouse and Gonzalez-Mena's (2004) go further and note that it is this on-going sharing of information about the child that continually alters each others perspectives of the child, building "a shared picture of the child" (p. 25).

In contrast, the positively framed dialogue on the ePortfolio was quite different to Whalley's (2007) description of dialogue. She described strong views being shared and challenged, which led to shared understandings between parents and teachers. The absence of this type of rigorous dialogue on the ePortfolio could be due to many reasons. For instance, the online etiquette prescribed when parents joined the ePortfolio site stated that communication was only to be framed in a positive manner. Guidelines for online participation are important to build trust in the online community (Booth, 2011) so an online platform may not be the place for the types of conversations that Whalley describes.

Much of the literature used different terminology in regards to goal consensus, potentially applying inconsistent interpretation of this concept. It could be helpful for teachers to discuss the meaning of shared aspirations, shared understandings, and goal consensus to ensure that they are working from the same understanding.

In summary, Bronfenbrenner's framework has been useful in deepening the analysis and findings of this study, particularly in terms of how types of communication linked to different elements of relational trust, how shared power was evident in an online 
environment, and raised questions regarding the different meanings of goal consensus. These points are further addressed in the concluding implications of this study.

\subsection{Contribution to research}

Much of the research on communication in ECE (e.g., Elliot, 2003; Hughes \& MacNaughton, 2001) drew on self-reported data obtained through surveys and interviews, and focused on either parents' or teachers' views. This study included parents', teachers', and families' views and also involved document analysis of stories. This resulted in triangulation of recorded online dialogue with self-reported experiences and perspectives, giving a clearer picture of how online communication was affecting and developing both relationships and ongoing learning.

These findings may be useful to services that see similarities between themselves and the description of this centre, and are using or considering introducing ePortfolios. Each service needs to consider their learning community and purpose before they introduce ePortfolios. Having parents and teachers in this study who were confident ICT users and who had access to ICT and the Internet positively influenced how the ePortfolio was used. The earlier use of a blog meant that issues of privacy, cyber safety, and online etiquette had been discussed, and policies and systems were in place to support these aspects.

The use of ePortfolios is growing rapidly in ECE and there is little research available to guide their use and effectiveness as a learning and communication tool. This research contributes to this knowledge base, filling a gap in the current research available. Bronfenbrenner's theoretical framework also provides a platform for further research concerning two-way communication.

\subsection{Limitations}

As this was a case study, there is limited generalisability for the wider early childhood community. As a small community based ECE centre (positioned in a suburb near a 
large city) that was well resourced, had $100 \%$ qualified teachers, and parents comfortable using ICT, this case study is not representative of all NZ ECE centres.

The ethical approval gained for this study required the use of a research assistant to undertake the teacher interviews so that I did not know their identity. Whilst supporting trustworthiness it limited my ability to gain understanding in several ways: first, the research assistant was less able to probe their responses in the interview than I would have been able to, as she didn't have the insider knowledge or in-depth knowledge of my on-going analysis. Second, some of the interview time was taken up with participants explaining to the research assistant how the ePortfolio functioned, potentially limiting the time available for deeper reflection. Finally, not knowing which teachers were interviewed meant that I was unable to connect individual teachers' data across the survey, interview and focus group to identify if particular points being made were from the same teacher or from across several teachers. There is, therefore, potential that I have over- or under-stated the importance or value of teachers' particular ideas or experiences.

Because none of the parents who responded in the survey that they never or seldom commented on the ePortfolio were willing to be interviewed, their perspectives have not been included. This perspective may have added greater depth and complexity to the study by understanding why this group of parents didn't engage with the ePortfolio.

In hindsight there were questions that could have been added or asked differently, which could have elicited more useful data. For example, asking for reasons for participants' choice after each quantitative question in the survey, rather than for examples, may have resulted in more in-depth data about why they selected that option.

The exemplar stories were selected using the criterion of the number of comments made on stories by teachers, parents, and wider whānau. The level chosen was five comments as an indicator of substantial two-way communication. In hindsight this may not have gathered stories that were the best exemplars of substantive dialogue. 


\subsection{Further research}

A number of questions and ideas for further research arose as I wrote this thesis. These include:

- In-depth case studies of individual children and their ePortfolios could offer further insights, especially in regards to how information shared on the ePortfolio supported children's on-going learning at home and at the service.

- Investigating links between online communication and the development of different elements of trust between parents and teachers.

- Investigating if there are differences between cultural and ethnic groups and their engagement with and use of ePortfolios.

- Exploring how different participants' purposes for using ePortfolios influences how they are used.

- The purpose of this study was to examine parent-teacher communication. In order to fully understand and value the use of ePortfolios, research is needed that examines children's experiences and perspectives of using ePortfolios.

\subsection{Concluding implications and issues arising from this study}

In conclusion, ePortfolios in this case study facilitated communication between teachers and parents, as well as with wider whānau and children to varying degrees. Six main implications from this study were identified:

While not all parents responded to stories written by teachers in the ePortfolio, there was still great value to parents in the one-way communication afforded by the ePortfolio. Teachers have a professional responsibility to work with and support all children and their families (MoE, 2008). It is important that teachers maintain a fair approach to ensure they are not engaging more with parents who are pro-active in 
online commenting. By monitoring which parents are not engaging with the ePortfolio teachers could explore what the barriers are for these parents, or ensure other methods of communication are being used instead. Having a clear purpose, as well as systems and processes in place is also important to ensure effective dialogue with parents is developed.

When online communication was more focused on affirmation and showing appreciation, the communication was more likely to support the building of relationships between parents and teachers. However, when information was shared, especially when it was specific and focused on the child, the communication was more inclined to enhance shared understandings, ultimately supporting the child's ongoing learning. Teachers could consider how to move from more surface online conversations to more substantive ones, especially as trust and relationships develop between parents and teachers. Writing more individual and small group stories that focus on learning, rather than more general stories written to the group, could also provide a private space for substantive dialogue between teachers and parents to develop.

Keeping learning foregrounded when communicating via the ePortfolio is key to supporting and enhancing children's learning over time. To facilitate this, teachers could articulate the types of comments that are helpful and why, and role-model these in their own commenting. When teachers use information given by parents to support children's learning, and document how they do this, parents see their comments are valued and how they influence their child's learning.

The trust element of benevolence was well developed between teachers and parents. To continue to build strong partnerships with parents, it is important that teachers reflect on how they build deeper, more complex elements of trust such as competence and openness, and consider what this might look like in an online environment.

The ePortfolio as a technological tool enabled communication to flow easily between settings. Anytime, anywhere access, instant email notification, and an easy to use platform were highly regarded features of the ePortfolio. It provided another avenue for communication to happen, and ultimately supported face-to-face communication. 
Having a wide range of avenues available to communicate with parents enabled more opportunity to reach a greater number of parents and whānau.

EPortfolios are still a very new technology in ECE and to ensure they don't become just another fad, research needs to continue into whether they are making a positive difference to children's learning. Drawing on this and other pertinent research while working pedagogically with ePortfolios, teachers can continue to develop practices that make a positive difference for children and their families. 
References:

Abrami, P., \& Barrett, H. (2005). Directions for research and development on electronic portfolios. Canadian Journal of Learning and Technology, 31(3). Retrieved from: http://www.cjlt.ca/index.php/cjlt/article/view/92/86

Adams, K., \& Christenson, S. (1998). Differences in parent and teacher trust levels. Special Services in the Schools. 14(1-2), 1-22.

Adams, K., \& Christensen, S. (2000). Trust and the family school relationship examination of parent-teacher differences in elementary and secondary grades. Journal of School Psychology, (38), 477-497.

Bernhard, J., Lefebvre, M., Kilbride, K., Chud, G., \& Lange, R. (1998). Troubled relationships in early childhood education: Parent-teacher interactions in ethnoculturally diverse child care settings. Early Education and Development, $9(1), 5-28$.

Billman, N., Geddes, C., Hedges, H. (2005). Teacher-parent partnerships: Sharing understandings and making changes. Australian Journal of Early Childhood, 30, (1), 44-48.

Bolstad, R. (2004). The role and potential of ICT in early childhood education. A review of New Zealand and international literature. Wellington, New Zealand: NZCER.

Booth, S. (2011). Cultivating knowledge sharing and trust in online communities for educators: A multiple-case study. Unpublished PhD Thesis, North Carolina State University. Raleigh, North Carolina.

Braun, V., \& Clarke, V. (2006). Using thematic analysis in psychology. Qualitative Research in Psychology, 3, 77-101.

Bronfenbrenner, U. (1979). The ecology of human development: Experiments by nature and design. Cambridge, MA: Harvard University Press. 
Carr, M. (2001). Assessment in early childhood settings. London: Paul Chapman Publishing.

Cherrington S., Oldridge L., Green V., Dalli C., Davidson S., Glasgow A., Rosewarne S., White E., \& Wansbrough D. (2009) Evaluation of the early childhood education information and communication technologies professional learning programme: Final report. Wellington: Ministry of Education.

Creswell, J. (2012). Educational research: Planning, conducting, and evaluating, quantitative and qualitative research $\left(4^{\text {th }}\right.$ ed.). Boston: Pearson Education Inc.

Denzin, N., \& Lincoln, Y. (Eds) (2000). Handbook of qualitative research (2nd ed). Thousand Oaks, CA: Sage.

Devito, J. (1995). Human communication ( $7^{\text {th }}$ ed.). New York: Longman.

Dunst, C., Johanson, C., Trivette, C., \& Hamby, D. (1991). Family-orientated early intervention policies and practices: Family centered or not? Exceptional Children, 58(2), 115-126.

Dunst, C. (2002). Family-centred practices: Birth through high school. The Journal of Special Education, 36(3), 139-147.

Education Review Office. (2008). The quality of assessment in early childhood education (November 2007). Wellington: Crown.

Elliot, R, (2003). Sharing care and education: Parents' perspectives. Australian Journal of Early Childhood, 28(4). 14-21.

Epstein, J. (2011). School, family, and community partnerships: Preparing educators and improving schools. Boulder, CO: Westview Press.

Ghazvini, A., \& Readdick, C. (1994). Parent-caregiver communication and quality of care in diverse childcare settings. Early Childhood Research Quarterly, 9, 207-222. 
Goddard, R., Tschannen-Moran, M., \& Hoy, W. (2001). A multilevel examination of the distribution and effects of teacher trust in students and parents in urban elementary schools. The Elementary School Journal, 102(1), 3-17.

Goodman, N. (2013a, June). Fostering quality parent and teacher engagement with children's learning using the Educa Online Portfolio System. Paper presented at the IECS Winter Research Seminar: Early Childhood Professional Learning: Growing the Profession/Growing the Community. Victoria University, Wellington.

Goodman, N. (2013b). Enhancing engagement using Educa online portfolios. The Space Magazine, 33. Spring, 24-25.

Hartnell-Young, E., Harrison, C., Crook, C., Joyes, G., Davies, L., Fisher, T., ... Smallwood, A. (2007). The impact of e-portfolios on learning. Coventry: Becta.

Hatherly, A., Ham, V., \& Evans, L. (2009). Effective learning in early childhood education? A synthesis report. Wellington: Ministry of Education.

Hatherly, A. (2010). The rise (and fall) of ICT in early childhood education. In eLearnings: Implementing a national strategy for ICT in education, 19982010. Christchurch: Core Education Ltd. 88-95.

Hattie J, (2009). Visible learning: A synthesis of over 800 meta-analyses relating to achievement. London: Routledge.

Hedges, H. (2010). Through the kaleidoscope: Relationships and communication with parents. The First Years, 12(1), 27-34.

Hughes, P., \& MacNaughton, G. (1999). Who's the expert: Reconceptualising parentstaff relations in early education. Australian Journal of Early Childhood, 24(4). 27-32.

Hughes, P., \& MacNaughton, G. (2001). Building equitable staff-parent communication in early childhood settings: An Australian case study. Early 
Childhood Research and Practice, 3(2)., para. 1-47. Retrieved from http://go.galegroup.com.helicon.vuw.ac.nz/ps/i.do?p=AONE\&u=vuw\&id= GALE\%7CA134162109\&\&v=2.1\&it=r\&userGroup=vuw\&authCount $=1$

Hughes, P., \& MacNaughton, G. (2011). Parents and professionals in early childhood settings. Berkshire: McGraw-Hill Education.

Janssen, M., Bakker, J., Bosman,K., \& Leseman, P. (2012). Differential trust between parents and teachers of children from low-income and immigrant backgrounds. Educational Studies, 38(4), 383-396.

Johnson, B., \& Christensen, L. (2012). Educational research: Quantitative, qualitative, and mixed approaches ( $4^{\text {th }}$ ed.). Thousand Oaks, CA: Sage Publications.

Lichtman, M. (2006). Qualitative research in education: A user's guide. London: Sage Publications.

Loveridge, J. (2002). Working with young children and their families in early education settings: The importance of dialogue and shared understandings. Delta: Policy and practice in education, 54 (1 \& 2), 171-191.

McGrath, W.H. (2007). Ambivalent partners: Power, trust, and partnership in relationships between mothers and teachers in full time childcare center. Teachers College Record, 109(6), 1401-1422.

MacNaughton, G. (2004). Children, staff and parents: Building respectful relationships in New Zealand and Australian early childhood contexts The Australian context. Australian Journal of Early Childhood, 29(1). para 1-60. Retrieved from http://go.galegroup.com.helicon.vuw.ac.nz/ps/i.do?id=GALE|A118416764 $\& \mathrm{v}=2.1 \& \mathrm{u}=\mathrm{vuw} \& \mathrm{it}=\mathrm{r} \& \mathrm{p}=\mathrm{AONE} \& \mathrm{sw}=\mathrm{w} \& \mathrm{asid}=1 \mathrm{bd} 17 \mathrm{f} 69 \mathrm{c} 1 \mathrm{~d} 69 \mathrm{a} 9 \mathrm{bddc} 50 \mathrm{e}$ $\underline{11 \mathrm{e} 19 \mathrm{c} 3 \mathrm{f} 15}$

MacNaughton, G., Rolfe, S. A., \& Siraj-Blatchford, I. (2001). Doing early childhood research: International perspectives on theory and practice. Buckingham, England: Open University Press. 
Martin, S. (2006). Opportunities for parent partnership and advocacy in early years services in Ireland. New Zealand Research in Early Childhood Education Journal, 9, 15-31.

Meade, A. (2012). Centre-parent communication about children's learning. Early Childhood Folio, 16(2). 38-43.

Meade, A., Robinson, L., Stuart, M., Smorti, S., \& Williamson, J., with Carroll-Lind, J., Meagher-Lundberg, P.,\& Te Whau, S. (2012) Early childhood teachers work in education and care centres: Profiles, patterns and purposes. Wellington: Te Tari Puna o Aotearoa/ New Zealand Childcare Association.

Merriam, S. (2012) Qualitative case studies. International Encyclopedia of Education ( $3^{\text {rd }}$ ed.). Elsevier Ltd, 456 - 462 doi:10.1016/B978-0-08-044894-7.015323

Ministry of Education. (1996). Te Whāriki: early childhood curriculum. Wellington: Learning Media.

Ministry of Education, (2004a). Kei tua o te pae Assessment for learning: Early childhood exemplars. Sociocultural assessment He Aromatawai Ahurea Pāpori. Wellington: Learning Media Ltd.

Ministry of Education, (2004b). Kei tua o te pae Assessment for learning: Early childhood exemplars. Assessment and learning: Community Te Aromatawai me te Ako: Hapori. Wellington: Learning Media Ltd.

Ministry of Education. (2005). Foundations for discovery. Wellington: Learning Media Ltd.

Ministry of Education. (2008). Licencing criteria for early childhood education and care centres 2008 and early childhood education curriculum framework. Wellington: New Zealand Government.

Mukherji, P., \& Albon, D. (2010). Research methods in early childhood: An introductory guide. London: Sage.

Newby, P. (2010). Research methods for education. Harlow: Pearson Education Ltd. 
New Zealand Council of Educational Research. (2007). First NZCER National Survey of Early Childhood Education Services: 2003-2004. Wellington: NZCER.

Osher, T., \& Osher, D. (2002). The paradigm shift to true collaboration with families. Journal of Child and Family Studies, 11(1), 47-60.

Perlman, M. \& Fletcher, B. (2012). Hellos and how are yous: Predictors and correlates of communication between staff and families during morning drop off in childcare centers. Early Education and Development, 23(4), 539-557.

Porter, L. (2008). Teacher-parent collaboration. Victoria: Acer Press.

Ramsey, K., Breen, J., Sturm, J., Lee, W., \& Carr, M. (2006). Roskill South kindergarten centre of innovation 2003-2006 final research report: Strengthening learning and teaching using ICT. Hamilton: University of Waikato.

Reedy, C., \& McGrath, W., (2010). Can you hear me now? Staff-parent communication in child care centres. Early Child Development and Care $180(3), 347-357$.

Rempel, J., Holmes, J., \& Zanna, M. (1985). Trust in close relationships. Journal of Personality and Social Psychology, 49(1), 95-112.

Rotorua Girls High School Childcare Trust (2009). E-portfolios as an effective communication tool in early childhood education: An action research [report]. Rotorua: Author.

Robinson, V., Hohepa, M., \& Lloyd, C. (2009). School leadership and student outcomes: Identifying what works and why: Best evidence synthesis iteration. Wellington: Ministry of Education.

Souto-Manning, M., \& Swick, K. (2006). Teachers beliefs about parent and family involvement; Rethinking our family involvement paradigm. Early Childhood Education Journal, 34(2), 187-193. 
Stonehouse, A., \& Gonzalez Mena, J. (2004). Making links: A collaborative approach to planning and practice in early childhood services. New South Wales: Pademelon Press.

Swick, K. (2003). Communication concepts for strengthening family-schoolcommunity partnerships. Early Childhood Education Journal, 30(4), 275280.

Sylva, K., Melhuish, E., Sammons, P., Siraj-Blatchford, I., \& Taggart, B. (2010). Early childhood matters: Evidence from the effective pre-school and primary education project. Oxon: Routledge.

Trivette, C., Dunst, C., \& Hamby, D. (1996). Characteristics and consequences of help giving practices in contrasting human services programs. American Journal of Community Psychology, 24(2), 273-293.

Whalley, M. (2007). Involving parents in their children's learning ( $2^{\text {nd }}$ ed.). London: Paul Chapman Publishing.

Wilgus, G. (2005). "If you carry him around all the time at home, he expects one of us to carry him around all day here and there are only TWO of us!" Parents', teachers', and administrators' beliefs about the parent's role in the infant/toddler center. Journal of Early Childhood Teacher Education, 26, 259-273.

Wilson, L., \& Dunst, C. (2005). Checklist for assessing adherence to family-centered Practices. CASEtools, 1(1) 1-6. Retrieved from http://fipp.org/static/media/uploads/casetools/casetools_vol1_no1.pdf

Yin, R. (2009). Case study research: Design and methods (4 ${ }^{\text {th }}$ ed.) Thousand Oaks, California: Sage Inc.

Zellman, G., \& Perlman, M. (2006). Parent involvement in childcare settings: conceptual and measurement issues. Early Child Development and Care, $176(5), 521-538$. 


\section{APPENDICES}

Appendix 1: Teachers' online survey

1. How long have you been using the ePortfolio?

$$
\begin{aligned}
& \text { 0-6 months } \\
& 7 \text { months - } 1 \text { year } \\
& 13 \text { months - } 2 \text { years }
\end{aligned}
$$

2 .How much do you think children's ePortfolio's have helped:

\begin{tabular}{l|l} 
& not at all \\
You communicate with \\
parents about childrens \\
learning \\
You to communicate with \\
wider family about children's \\
learning \\
You to communicate with \\
other teachers about \\
children's learning \\
You to support children's \\
ongoing learning \\
$\begin{array}{l}\text { Parents to communicate with } \\
\text { you about their child's life } \\
\text { outside the centre } \\
\text { Strengthen the } \\
\text { communication between the } \\
\text { centre and home } \\
\text { Strengthen the relationship } \\
\text { between you and parents } \\
\text { Parents to share their } \\
\text { aspirations for their child } \\
\text { while they are at the centre }\end{array}$
\end{tabular}

3. How often do you comment on children's stories in the ePortfolio?

$\begin{array}{ll}\square & \text { never } \\ \square & \text { seldom } \\ \square & \text { occasionally } \\ \square & \text { often } \\ \square & \text { always }\end{array}$

4. If you answered occasionally, often, or always, what are your reasons for commenting?

5. If you answered never or seldom, what are your reasons for not commenting? 
6. In what ways do parents and wider family respond to your comments?

7. During the time that you have been using the ePortfolio, have there been any shifts in the number of comments you make?

$\begin{array}{ll}\square & \text { yes } \\ \square & \text { no } \\ \square & \text { other: }\end{array}$

8. Have there been any shifts in the type of comments you make?

$\begin{array}{ll}\square & \text { yes } \\ \square & \text { no } \\ \square & \text { Other: }\end{array}$

9. If you answered 'yes' to either of the above questions can you please explain how your comments have changed

10. What are the most important reasons why you communicate with parents via the ePortfolio?

11. Can you give an example?

12. In what ways do you encourage comments from parents and wider family?

13. What ways have you found most successful?

14. What ways have you found least successful?

15. What do you think are the most important reasons for communicating with parents?

16. How important to you is it to incorporate further learning opportunities into your stories?

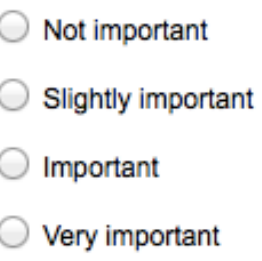

17. Why? 
18.

Two way communication can be influenced by various factors, such as shared trust. I am interested in this because the communication you have with parents and whânau may be online through the ePortfolio as well as through face-to-face interactions at the centre. Please can you tick the box that best represents your general experience with parents.

In my experience the parents generally:

\begin{tabular}{|c|c|c|c|c|c|}
\hline & $\begin{array}{l}\text { strongly } \\
\text { disagree }\end{array}$ & Disagree & $\begin{array}{c}\text { Neither Agree } \\
\text { nor Disagree }\end{array}$ & Agree & Strongly Agree \\
\hline $\begin{array}{l}\text { Provide me with all the } \\
\text { information I need related to } \\
\text { their child }\end{array}$ & & & O & O & O \\
\hline $\begin{array}{l}\text { Are easy to reach when I } \\
\text { have a problem or question }\end{array}$ & & & & & \\
\hline $\begin{array}{l}\text { Are friendly and } \\
\text { approachable }\end{array}$ & & & & & \\
\hline $\begin{array}{l}\text { Take me seriously when I ask } \\
\text { a question }\end{array}$ & & & & & \\
\hline $\begin{array}{l}\text { Encourage their child to have } \\
\text { a positive attitude toward } \\
\text { learning }\end{array}$ & & & & & \\
\hline $\begin{array}{l}\text { Respect me as a competent } \\
\text { teacher }\end{array}$ & & & & & \\
\hline $\begin{array}{l}\text { Supply information that is } \\
\text { correct and reliable }\end{array}$ & & & & & \\
\hline Care about their child & O & $\bigcirc$ & O & O & O \\
\hline
\end{tabular}

Is there anything else you would like to add in regards to your experience with ePortfolios?

19. Would you be interested in taking part in a follow up interview?

$$
\begin{aligned}
& \text { yes } \\
& \text { no } \\
& \text { maybe }
\end{aligned}
$$

If you ticked yes or you would like more information please enter your email address so I can contact you:

20. Would you like to receive a summary of the survey once the thesis is written?<smiles>C1CCC2CCCC2C1</smiles>

If you ticked yes please enter your email address: 
Appendix 2: Information and consent for survey

to go on first webpage of survey:

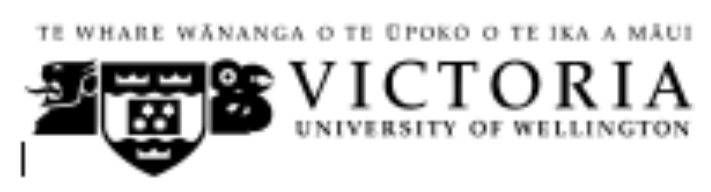

\section{INFORMATION SHEET:}

\section{Masters Project: Electronic Portfolios in Early Childhood Education}

You are invited to participate in a research study investigating how electronic portfolios (ePortfolios) facilitate communication between families and teachers. This sheet provides you with information about the project.

\section{Research design}

My research design involves undertaking a single case study at your centre. For my project I intend to focus on four specific questions:

. How do ePortfolios facilitate communication between families and teachers in an early childhood centre?

- What type of communication is fostered through the use of ePortfolios in an early childhood centre?

. How do teachers' values and beliefs about communicating with families influence communication through ePortfolios in an early childhood centre?

- What impact does communication through the use of ePortfolios have on teacherparent relationships and understandings about children's learning?

The questions investigate the notion of two-way communication built on trust, shared 
power, and a consensus of goals (Bronfenbrenner, 1979). I am interested in understanding how the ePortfolio facilitates communication, and how different types or styles of stories may encourage different types of communication. In regards to the third question I am interested in how teachers beliefs and values potentially influence the way they write the stories and comment, and what this means for communication with parents. The last question investigates what difference this communication has made to relationships and children's learning - the 'so what?' question.

\section{Ethical approval}

This Masters thesis research project has been approved by the Faculty of Education Human Ethics Sub-committee under delegated authority from the Victoria University Human Ethics Committee (No. SEPP/2013/0000020286). If you have any ethical concerns about this project, please contact the Chair of Victoria University of Wellington Human Ethics Committee, Dr. Allison Kirkman (Allison.kirkman@vuw.ac.nz; phone (04) 463 5676).

The identity of the centre and participating teachers and families in the project will remain confidential in the written thesis and any papers that are prepared for presentation and/or publication. Pseudonyms will be used for the staff, families and centre, and children identified by letters only (e.g., Child A, Child B).

If you would like to discuss any aspect of this project further, my contact details are as follow: Amanda Higgins Phone: (04) 4726885 or (0274) 888313 Email: amanda.higgins@xtra.co.nz

My supervisor, Sue Cherrington, is also available to discuss any issues that prospective participants may have about the research project, either prior to agreeing to participate or during the actual case study period. Her contact details are:

Dr. Sue Cherrington Phone: (04) 4639552 Email: sue.cherrington@vuw.ac.nz

\section{Next page on Qualtrics:}

Thank you for taking the time to complete the following survey. This survey is part of 
the data collection for my Masters thesis investigating electronic portfolios and communication between families and teachers.

By continuing with this survey, you are deemed to have given your consent to participate in this project. You have the right of withdrawal from this survey up until the time that you submit the survey.

If you have more than one child at the centre please answer this survey in relation to your eldest child.

To begin the survey, please click on the right arrow button at the bottom of the page. This will take you to the first section of the questionnaire. Use this button to proceed to each new section of the questionnaire. If you wish to return to a previous section please use the left arrow button. Please do not use the forward and back buttons on your web browser as these will take you out of the survey.

You will not be identified in any way in the thesis or any subsequent publications or presentations. Results will be reported across the respondents. Individual quotes may be used to illustrate the results.

I do appreciate your participation in this survey - your contribution will help strengthen the research knowledge of how ICT tools, namely electronic portfolios contribute to communication between the wider family and teachers.

Kind regards

Amanda Higgins Masters thesis student 


\section{.

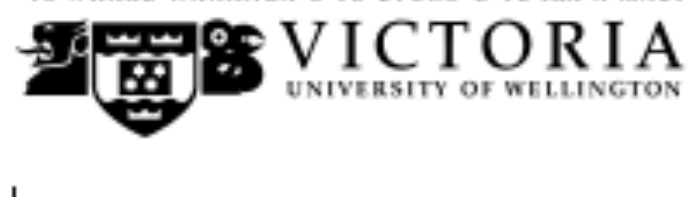

Kia ora

\section{INFORMATION SHEET:}

Masters of Education Project: Electronic Portfolios in Early Childhood Education

You are invited to participate in a research study investigating how electronic portfolios (ePortfolios) facilitate communication between families and teachers. This sheet provides you with information about the project and includes an informed consent form for you to sign if you are willing to be a participant in the project.

If you volunteer to participate you will be asked to complete an online questionnaire. You will also be asked to give consent for the researcher to view your entries/stories and comments on the centre's ePortfolio. You may also be invited to participate in a further indepth interview, a focus group interview, and be observed when parents pick their children up at the end of the day (additional informed consent will sought for these activities). The three teachers to participate in the semi structured interview, focus group, and observation will be selected via the survey, where they have indicated their interest in participating. From this group the three selected will reflect a wide range of responses to how they comment on the centres ePortfolio - one who has commented frequently, one who has commented occasionally, and one who has rarely or not commented. If there are not participants that meet these criteria the next closest participant will be selected. The individual interview will be held at a time and place that is convenient to you, and should take one hour. The focus group interview will take place at the centre at a time and date that suits as many participants as possible. My research assistant will facilitate both the interview and the focus group. This is to remove any potential bias in regards to our previous relationship. 
The observation will be of conversations between parents and teachers at the end of the day when the parent picks up their child. While I will be specifically observing the five parents and three teachers who will take part in the interview and focus groups, these observations may involve others that these participants talk to. No data will be collected about the identity of any other person who is involved in this conversation, other than that they are a parent or teacher. Only non-verbal and verbal cues used, number of times each person talks, and general topic of conversation will be recorded.

\section{Research design}

My research design involves undertaking a single case study at your centre. For my project I intend to focus on four specific questions:

1. How do ePortfolios facilitate communication between families and teachers in an early childhood centre?

2. What type of communication is fostered through the use of ePortfolios in an early childhood centre?

3. How do teachers' values and beliefs about communicating with families influence communication through ePortfolios in an early childhood centre?

4. What impact does communication through the use of ePortfolios have on teacher-parent relationships and understandings about children's learning?

The questions investigate the notion of two-way communication built on trust, shared power, and a consensus of goals (Bronfenbrenner, 1979). I am interested in understanding how the ePortfolio faciltates communication, and how the way stories are written may facilitate different types of communication. In regards to the third question I am interested in how teachers' beliefs and values potentially influence the way they write the stories and how they comment, and what this means for communication with parents. The last question investigates what difference this communication has made to relationships and childrens learning - the 'so what?' question.

\section{Data gathering processes}

The data gathering will involve me working with the centre over the period of approximately ten months. 
Data gathering activities will include:

- An initial visit in order to discuss in detail the research processes and address any issues that teachers and families may have about the research, including confidentiality, presentation and publication of findings.

- December 2013: Collect and analyse children's stories and subsequent comments on the ePortfolio from parents and teachers that have given informed consent. This will be able to be done remotely so I will not need to be in at the centre.

- February 2014: Send out surveys via email to all participating families and teachers. Again this can be done remotely. If I get a less than $30 \%$ return rate I may choose to also send out a paper copy of the survey via the centre's information pockets.

- March - May 2014: Conduct interviews with five parents and three teachers. These interviews will be audio-taped to assist with the transcription of the data. Each interview would probably take one hour and will take place during teachers' non-contact time or in the evening, so they will not disrupt the programme (further informed consent will be sought for these).

- June 2014: Conduct focus group meetings. These meetings will be audio recorded and written notes will be taken but audio recordings will not be transcribed.

- July - August 2014: Spend approximately two afternoons per week in the centre undertaking narrative observations of the five interview parents when they pick their child up at the end of the day, and the three interview teachers when families pick their children up at the end of the day (further informed consent will be sought for this).

\section{Ethical approval}

The Thesis research project has received approval from the Faculty of Education Human Ethics Sub-committee under delegated authority from the Victoria University Human Ethics Committee (Approval No. SEPP/2013/0000020286). If you have any ethical concerns about this project, please contact the Chair of Victoria University of 
Wellington Human Ethics Committee, Dr. Allison Kirkman (Allison.kirkman@vuw.ac.nz; phone (04) 463 5676).

\section{Informed consent}

Participation in this project requires your informed consent. Attached to this information sheet is a consent form which needs to be completed and returned to me, if you are willing to be a participant in the project.

The identity of the centre and participating teachers in the project will remain confidential in the written thesis and any papers that are prepared for presentation and/or publication. Pseudonyms will be used for the staff, families and centre, and children identified by letters only (e.g., Child A, Child B). Because of my previous association with the centre there is a possibility that readers of the thesis may recognise the centre. To minimise the possibility of this happening I will carefully frame the information I provide about the centre and my association with it. I will also only refer to 'teachers' and not their positions in my writing to reduce the potential for individual recognition.

\section{Withdrawal from the project}

You have the right to withdraw from the project without giving any reason up until the completion of the data gathering phase, being August 2014.

\section{Researcher/participant relationships}

Because this project would involve me working with you in a potentially different professional capacity, during the initial orientation visit it will be important to discuss how we will work together as researcher and research participants, especially in regards to how any potential negative findings will be reported. My supervisor, Sue Cherrington, is also available to discuss any issues that prospective participants may have about the research project, either prior to agreeing to participate or during the actual case study period. Her contact details are:

\section{Dr. Sue Cherrington}


Phone: (04) 4639552

Email: sue.cherrington@vuw.ac.nz

Thank you for considering involvement in the project. If you would like to discuss any aspect of this project further, my contact details are as follow:

Amanda Higgins

Phone: (04) 4726885 or (0274) 888313

Email: amanda.higgins@xtra.co.nz

Yours sincerely

Amanda Higgins 


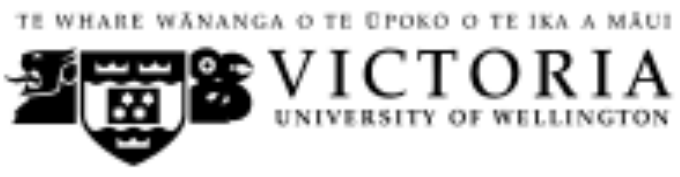

\section{TEACHERS' CONSENT FORM FOR ACCESSING EPORTFOLIOS AND BEING OBSERVED WHEN CHILDREN ARE BEING PICKED UP}

\section{Masters Project: Electronic Portfolios in early childhood education}

I have read and understood the attached information sheet for teachers and understand that I can withdraw my consent to use any documentation of child's learning that I have written at any time up until completion of the data collection, being August 2014.

I give my consent for the following aspects of the case study:

$\square \mathrm{I}$ agree that documentation I have written that is part of our centres electronic portfolio may be copied, photographed, discussed, and included in the data collection procedures.

$\square$ I agree that any online comments made by myself may be copied, photographed, discussed, and included in the data collection procedures.

$\square \mathrm{I}$ agree that I may be observed when a parent participating in the research picks up their child. I understand I may only be observed when talking with a parent. I will only be identified as a teacher and only the general topic of the conversation will be recorded.

Name of Teacher:

Signature of Teacher: 
(optional)

$\square$ I would like a copy of the thesis upon completion of the project.

Email address for it to be sent to: 


\section{PARENT/GUARDIAN CONSENT FORM FOR ACCESSING CHILDS EPORTFOLIO AND BEING OBSERVED WHEN PICKING CHILD UP}

Masters project: Electronic portfolios in early childhood education

I have read and understood the attached information sheet for parents/guardians and understand that I can withdraw my consent to use any documentation of my child's learning at any time up until completion of the data collection, being August 2014.

I give my consent for the following aspects of the case study:

$\square$ I agree that documentation of my child's learning that is part of her/his electronic portfolio may be copied, photographed, discussed, and included in the data collection procedures.

$\square$ I agree that any online comments made by myself, my child, or anyone I have invited onto the ePortfolio, may be copied, photographed, discussed, and included in the data collection procedures.

$\square$ I agree that I may be observed when I am in the centre to pick up my child. I understand I will only be observed when talking with a teacher. I will only be identified as a parent and only the general topic of the conversation will be recorded.

Name of Child/ren: 
Name of Parent/Guardian:

Signature of Parent/Guardian:

(optional)

$\square \quad$ I would like a copy of the thesis upon completion of the project.

Email address for thesis to be sent to: 
Appendix 5: Interview protocol

\begin{tabular}{|c|c|}
\hline Welcome & $\begin{array}{l}\text { - Welcome, my name is Karen and I am the research assistant for Amanda } \\
\text { - I appreciate your time } \\
\text { - Try to speak in a clear voice } \\
\text { - No right or wrong answers - want to know your opinions } \\
\text { - The interview should take an hour at the most }\end{array}$ \\
\hline Purpose & $\begin{array}{l}\text { - The purpose of this interview is to hear about your experiences with [the } \\
\text { ePortfolio platform], and in particular how you have communicated with parents, } \\
\text { whānau, and other teachers with it, and any differences this has made for you and } \\
\text { children. } \\
\text { - Amanda is completing her thesis on electronic portfolios and communication } \\
\text { between teachers and families. This interview will help inform this research. To } \\
\text { ensure there is no researcher bias Amanda does not know who is being } \\
\text { interviewed. Because of this some questions I ask may relate to some answers } \\
\text { from the survey, though it may not relate to your answer. I have signed a } \\
\text { confidentiality agreement so I cannot repeat anything you say. }\end{array}$ \\
\hline Guidelines & $\begin{array}{l}\text { - I'll just remind you that the recording of this will be transcribed, who has also } \\
\text { signed a confidentiality agreement. } \\
\text { - To ensure your anonymity you will be assigned a pseudonym for the transcript, } \\
\text { the data analysis and the final thesis. } \\
\text { - If anyone else is identified in the interview this identity will be also be given a } \\
\text { pseudonym by the transcriber to keep your anonymity. } \\
\text { - You will have an opportunity to peruse the transcript and make any changes to } \\
\text { inaccuracies or errors. } \\
\text { - The recording will be destroyed within five years of the completion of the } \\
\text { project. } \\
\text { What questions do you have for me about the process? }\end{array}$ \\
\hline $\begin{array}{l}\text { Warm- } \\
\text { up/build } \\
\text { rapport }\end{array}$ & $\begin{array}{l}\text { So tell me a little of how you have used the ePortfolio in the last month? } \\
\text { We'll move onto the interview now. }\end{array}$ \\
\hline
\end{tabular}




\begin{tabular}{|c|c|c|}
\hline interview & $\begin{array}{l}\text { How do ePortfolios } \\
\text { facilitate } \\
\text { communication } \\
\text { between families and } \\
\text { teachers? }\end{array}$ & $\begin{array}{l}\text { What do you think are the main themes or information } \\
\text { communicated through the ePortfolio? } \\
\text { How have you used the ePortfolio to communicate with } \\
\text { parents? (could be stories, trips, newsletters, self review) } \\
\text { Prompts: have you used any of the features such as the } \\
\text { community page or child's notes? } \\
\text { What difference has this made? } \\
\text { Can you give some examples? } \\
\text { Do you see this format an equal balance of sharing? Why? } \\
\text { Why not? }\end{array}$ \\
\hline & $\begin{array}{l}\text { What type of } \\
\text { communication is } \\
\text { fostered through the } \\
\text { use of ePortfolios? }\end{array}$ & $\begin{array}{l}\text { Many of the teachers felt that ePortfolio had little affect on } \\
\text { parents sharing their inspirations for their children, why do } \\
\text { you think that is? } \\
\text { What types of commenting do you mostly receive from } \\
\text { parents? } \\
\text { (prompts - appreciation, links to home, interests, } \\
\text { commenting about what they are doing) } \\
\text { Why do you think this is? } \\
\text { What types of comments do you mostly make? } \\
\text { (could be appreciation, extending the learning, showing } \\
\text { interest) prompts: } \\
\text { Do you notice any difference in the commenting between } \\
\text { individual and group stories? } \\
\text { Why do you think this is? } \\
\text { What are some of the enablers and barriers to you } \\
\text { commenting? }\end{array}$ \\
\hline
\end{tabular}




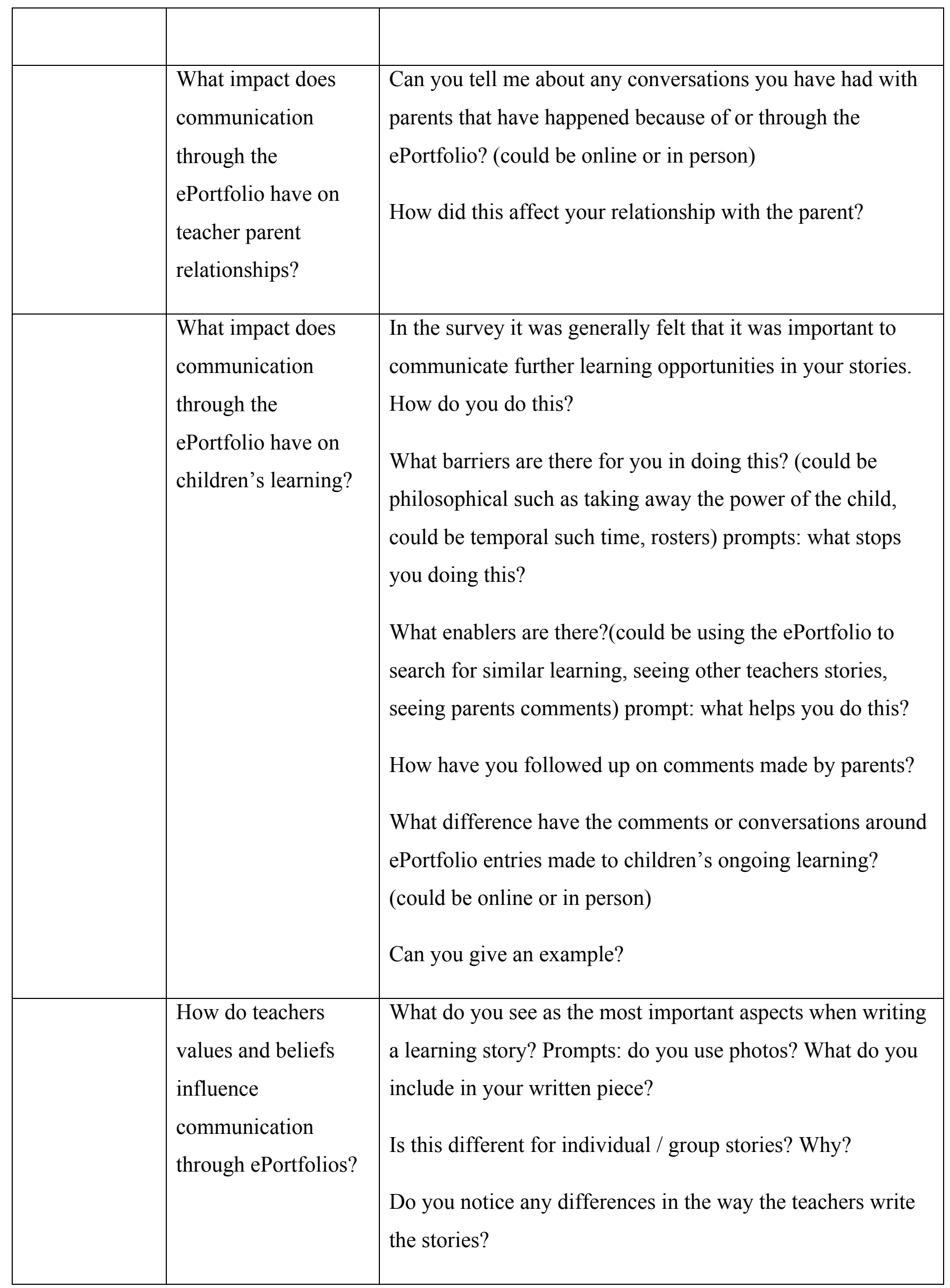




\begin{tabular}{|l|l|l|}
\hline \multirow{l}{*}{} & & $\begin{array}{l}\text { Do you have a preferred style of writing? Why? } \\
\text { Do you notice any difference in the way teachers comment? } \\
\text { What are the most important things to you when you are } \\
\text { communicating with parents via the ePortfolio? Can you } \\
\text { strategies } \\
\text { give an example? }\end{array}$ \\
\hline $\begin{array}{l}\text { Euestion } \\
\text { interview }\end{array}$ & $\begin{array}{l}\text { Use elaboration, probing, wait time } \\
\text { Anything else? }\end{array}$ \\
& $\begin{array}{l}\text { Any other reason? } \\
\text { Thank you for participating }\end{array}$ \\
\hline
\end{tabular}


Appendix 6: Transcriber confidentiality agreement

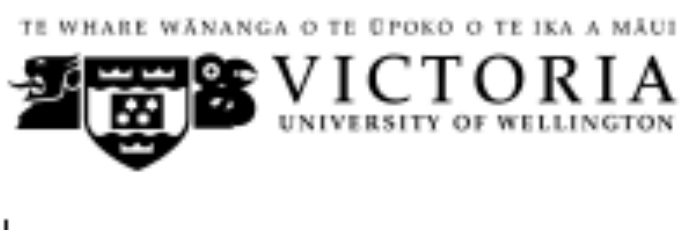

TRANSCRIBER CONFIDENTIALITY AGREEMENT

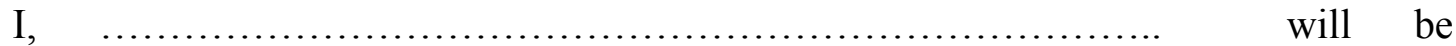
transcribing interviews for the Masters research project - Electronic portfolios in early childhood.

No names of participants or identification of the ECE centre will be provided to me. Furthermore, all the information that is provided will be deemed confidential and I will ensure that it is not released to any third party.

Name of transcriber:

Signature of the transcriber:

Date 
Appendix 7: Centre permission form

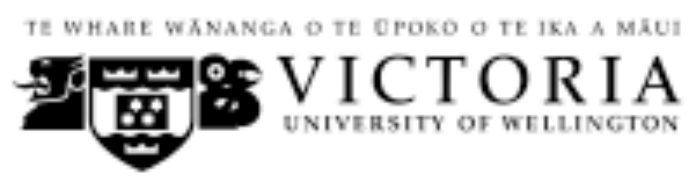

Kia ora

\section{Masters Project: Electronic Portfolios in Early Childhood Education}

I am investigating how electronic portfolios facilitate communication between families and teachers. This letter is to inform you of the project and to seek your approval as the centre's Management Committee to undertake research at your early childhood centre.

My research design involves undertaking a single case study. For my project I intend to focus on four specific questions:

- 1) How do electronic portfolios (ePortfolios) facilitate communication between families and teachers in an early childhood centre?

2) What type of communication is fostered through the use of ePortfolios in an early childhood centre?

3) How do teachers' values and beliefs about communicating with families influence communication through ePortfolios in an early childhood centre?

4) What impact does communication through the use of ePortfolios have on teacher-parent relationships and understandings about children's learning?

The data gathering would involve me working with your centre over the period of approximately ten months.

Data gathering activities will include:

- An initial visit in order to discuss in detail the research processes and address any issues that teachers and families may have about the research.

- November 2013: gaining informed consent from teachers and parents and verbal 
assent from children.

- December 2013: Collect and analyse children's stories and associated online comments on the ePortfolio from parents and teachers that have given informed consent. This will be able to be done remotely so I will not need to be in at the centre.

- February 2014: Send out an online survey via email to all families. Again this can be done remotely. If I get a less than a $30 \%$ return rate I may choose to also send out a paper copy of the survey via the centre's information pockets.

- March - May 2014: Conduct interviews with five parents and three teachers. These interviews will be audio-taped to assist with the transcription of the data. Each interview would probably take one hour and will take place during teachers' non-contact time or in the evening, so they will not disrupt the programme.

- June 2014: Conduct a focus group meeting. These meetings will be audio recorded and written notes will be taken but audio recordings will not be transcribed.

- July - August 2014: Spend approximately two afternoons per week in the centre undertaking narrative observations of the five parent interviewees when they pick their child up at the end of the day, and the three teacher interviewees when families pick their children up at the end of the day. The three teachers and five parents to participate in the semi structured interview, focus group, and observation will be selected via the survey, where they have indicated their interest in participating. From this group the three teachers selected will reflect a wide range of responses to how they comment on the centres ePortfolio - one who has commented frequently, one who has commented occasionally, and one who has rarely or not commented. The five parents selected to participate will reflect a wide range of responses to how they comment on their child's ePortfolio - one who has commented frequently, one who has not commented, one who has changed in the amount they comment, one who has changed in the way they comment, and one that occasionally comments. Participants also need to have children attending the centre who will not turn five before the end of July 2014 so they are available for the 
focus group. If there are not participants that meet these criteria the next closest participant will be selected. My research assistant will facilitate the focus group and I will be a silent observer and recorder. The research assistant will also conduct the interview if I have known teachers or parents previously. This is to remove any potential bias in regards to our previous relationship. The identity of the centre and participating teachers and families will remain confidential in the written thesis and any papers that are prepared for presentation and/or publication. Pseudonyms will be used for the staff and centre, and children identified by letters only (e.g., Child A, Child B). Because of my previous association with the centre there is a possibility that readers of the thesis may recognise the centre. To minimise the possibility of this happening I will carefully frame the information I provide about the centre and my association with it. Teachers and families can receive a copy of the thesis at the conclusion of the research if they wish. Each teacher and parent has the right to withdraw from the project without giving a reason up until the completion of the data gathering phase, being August 2014. The Masters thesis research project has been approved by the Faculty of Education Human Ethics Sub-committee under delegated authority from the Victoria University Human Ethics Committee (No.SEPP/2013/0000020286). If you have any ethical concerns about this project, please contact the Chair of Victoria University of Wellington Human Ethics Committee, Dr Allison Kirkman (Allison.kirkman@vuw.ac.nz; phone (04) 463 5676). If you have further questions about the project I am very happy to discuss these with you, either at a Management Committee meeting, email or by telephone. My contact details are: Amanda Higgins Phone: (04) 4726885 (0274) 888313 Email: amanda.higgins@xtra.co.nz

My supervisor, Dr. Sue Cherrington is also available to discuss any issues that the Management Committee or the teachers may have about the research project. Her contact details are:

Dr. Sue Cherrington Phone: (04) 4639552 Email: sue.cherrington@vuw.ac.nz

Yours sincerely 
Amanda Higgins Masters thesis student 
Masters Project: Electronic portfolios in early childhood education Approval for Centre to participate in the project

I have been given and have understood an explanation of this research project. I have had an opportunity to ask questions and have them answered to my satisfaction.

I understand that the research may be presented in the thesis and in academic or professional journals or at educational conferences.

I understand that the name of our ECE service, staff, families, and children will not be revealed in any publications or presentations arising from this research, instead pseudonyms will be used.

I understand that the data collected will be kept secure. Only the researcher and her supervisor will have access to the data. I also understand that all the data collected will be destroyed 5 years after the conclusion of the research project.

I give Amanda Higgins permission to undertake a case study as part of her Masters research in centre.

I do not give Amanda Higgins permission to undertake a case study as part of her Masters research in centre.

Signed: Name (please print clearly):

Chair, Centre Management Team

Date: 
Appendix 8: Second level of information and consent for interview and focus group participants

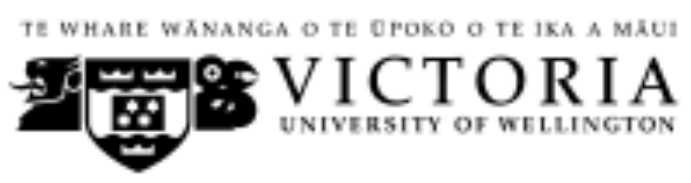

Kia ora

\section{INFORMATION SHEET:}

\section{Masters Project: Electronic Portfolios in Early Childhood Education}

Thank you for your interest in being further involved in this research project. This sheet provides you with information about the continuing project and includes an informed consent form for you to sign if you are willing to be a participant.

If you volunteer to participate you will be asked to participate in an in-depth interview, teacher focus group, and be observed when parents pick up their child at the end of the day on approximately three occasions.

- The individual interview will be held at a time and place that is convenient to you, and should take approximately one hour. This interview will be conducted by my research assistant to reduce the potential of researcher bias. This interview will be audio taped to assist with the transcription of the data. A transcriber will be used to transcribe the interview and they will have signed a confidentiality agreement. Once this is done the transcribed interview will be returned to you to check for accuracy. Only my supervisor, research assistant, the transcriber, and myself will see this data. It will be kept in a locked cabinet or password-protected computer for a period of five years after the study is completed and then destroyed. Your identity will be kept confidential except to my supervisor, my research assistant, and myself. You will not be identified in any subsequent writing of the project; instead a pseudonym will be used if necessary. 
- The focus group interview will take place at the centre at a time and date that suits as many of the three teacher participants as possible. This will be approximately one hour in duration and will include the checking of my interpretations of the data thus far into the project, and any new questions I may have that have arisen from the interview phase of the project. The focus group interview will be audio taped but not transcribed. The research assistant will facilitate this meeting and I will be a silent observer and note taker. The audio recording will be used to revisit and check on general themes of the conversation. The audio recording will be kept either in a locked cabinet or a password protected computer for a period of five years and then destroyed.

- I will conduct three narrative written observations of you when parents pick up their children at the end of the day over a period of several weeks. This will focus on the interaction between you and the parent/s. I envisage I would be in the centre from $4.15 \mathrm{pm}-5.30 \mathrm{pm}$ depending on your shift. My notes will be kept in a locked cabinet or password-protected computer for a period of five years after the study is completed, and then destroyed.

\section{Ethical approval}

The evaluation project has been approved by the faculty of Education Human Ethics Subcommittee under delegated authority from the Victoria University Human Ethics Committee (No. SEPP/2013/ 0000020286). If you have any ethical concerns about this project, please contact the Chair of Victoria University of Wellington Human Ethics Committee, Dr Allison Kirkman (Allison.kirkman@vuw.ac.nz; phone (04) 463 5676)

\section{Informed consent}

Participation in this project requires your informed consent. Attached to this information sheet is a consent form which needs to be completed and returned to me, if you are willing to be a participant in the project.

The identity of the centre and participating teachers and famillies in the project will remain confidential in the written thesis and any papers that are prepared for presentation and/or 
publication. Pseudonyms will be used for the staff, families and centre, and children identified by letters only (e.g., Child A, Child B).

\section{Withdrawal from the project}

You can withdraw from the research project at anytime until the data collection phase is completed, being August 2014.

Thank you for considering involvement in the project. If you would like to discuss any aspect of this project further, my contact details are as follow:

Amanda Higgins

Phone: 4726885 or (0274) 888313

Email: amanda.higgins@xtra.co.nz

My supervisor, Sue Cherrington, is also available to discuss any issues that prospective participants may have about the research project, either prior to agreeing to participate or during the actual case study period. Her contact details are:

Dr. Sue Cherrington

Phone: (04) 4639552

Email: sue.cherrington@vuw.ac.nz

Ngā mihi

Amanda Higgins

Master thesis student 


\section{TE WHAIE WANANGA O TE OPOKO O TE IKA A MAUI 590. VICTORIA}

\section{TEACHER CONSENT FORM FOR INTERVIEW, FOCUS GROUP, AND OBSERVATION}

\section{Masters Project: Electronic portfolios in early childhood education}

Please tick the appropriate box and sign at the bottom of the page to indicate your agreement with the statements and to provide informed consent for participation in this project.

I have been given and have understood an explanation of this research project. I have had an opportunity to ask questions and have them answered to my satisfaction.

I understand that I may withdraw myself (or any information I have provided) from this project (before data collection is complete, being August 2014) without having to give reasons or without penalty of any sort.

I understand that the data collected will be kept confidential to the researcher and her supervisor, and the person who transcribes the tape recordings of the interview will be asked to sign a confidentiality agreement.

I understand that the tape recordings of interviews and focus groups will be electronically wiped or destroyed within five years of the conclusion of the project.

I understand that the published results will not use my name or the name of the centre, or include descriptions that in any way identify me or the centre.

I understand that I will have an opportunity to review the transcripts of the interview for errors before publication.

I understand that the data I provide will not be used for any other purpose or released to others.

I agree to take part in this research.

I do not agree to take part in this research. 
Signed:

Name of participant (please print clearly)

Date:

Optional:

I would like to receive a copy of the thesis at the conclusion of the research.

If you have ticked the box please provide your email address: 
Appendix 9: Research assistant confidentiality agreement

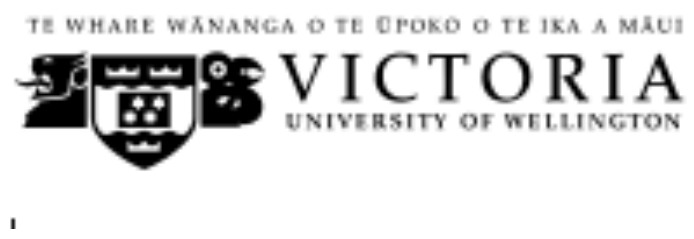

RESEARCH ASSISTANT CONFIDENTIALITY AGREEMENT

$\mathrm{I}$,

will be conducting

teacher and parent interviews and facilitating the focus groups for the research project 'E-portfolios in early childhood education'. I will also ensure that I adhere to the ethical requirements for this research project, as outlined by the principal investigator.

All the information that is provided to me will be deemed confidential and I will ensure that it is not released to any third party.

Name of research assistant:

Signature of the research assistant

Date 
Appendix 10: Table outlining different codes for data sources

\begin{tabular}{|l|l|}
\hline Exemplar stories & ES \\
\hline Teacher survey & TS \\
\hline Parent survey & PS \\
\hline Wider whānau survey & WWS \\
\hline Teacher interview & TI \\
\hline Parent interview & PI \\
\hline
\end{tabular}


Appendix 11: Theme descriptions of parent survey

\begin{tabular}{|c|c|c|c|}
\hline Parent survey & & & \\
\hline Theme & node & explanation & example \\
\hline $\begin{array}{l}\text { Challenges/barri } \\
\text { ers/concerns }\end{array}$ & & $\begin{array}{l}\text { challenges or concerns } \\
\text { since using ePortfolios }\end{array}$ & $\begin{array}{l}\text { If it weren't for clubs, I don't think there } \\
\text { would be many [stories] of my child. }\end{array}$ \\
\hline \multirow[t]{2}{*}{$\begin{array}{l}\text { Enabler of web } \\
\text { platform/tools }\end{array}$} & Ease of use & $\begin{array}{l}\text { tools that facilitate use } \\
\text { of the ePortfolio. } \\
\text { 'easy' often mentioned }\end{array}$ & $\begin{array}{l}\text { There wasn't a "place" to write feedback } \\
\text { in the profile books and so being able to } \\
\text { write comments has made for a more } \\
\text { two (and multi) way communication } \\
\text { with teachers and other parents. }\end{array}$ \\
\hline & wider whānau & $\begin{array}{l}\text { Ease of sharing with } \\
\text { wider family }\end{array}$ & $\begin{array}{l}\text { it is a great way to share information } \\
\text { about his learning with family who live } \\
\text { out of town. }\end{array}$ \\
\hline $\begin{array}{l}\text { Barrier of the } \\
\text { web } \\
\text { platform/tools }\end{array}$ & & $\begin{array}{l}\text { Tools that distract } \\
\text { from the } \\
\text { communication }\end{array}$ & $\begin{array}{l}\text { Getting group comments from other parents } \\
\text { can be a bit annoying }\end{array}$ \\
\hline \multirow[t]{2}{*}{ Benefit } & $\begin{array}{l}\text { Being } \\
\text { informed }\end{array}$ & $\begin{array}{l}\text { Parents mention being } \\
\text { informed about what } \\
\text { is happening for their } \\
\text { child while at the } \\
\text { centre. Typical } \\
\text { language used: 'see' } \\
\text { 'find out' 'know' }\end{array}$ & $\begin{array}{l}\text { The e-portfolio allows us to see a lot } \\
\text { more of the child's day-to-day activities } \\
\text { that we otherwise wouldn't see. }\end{array}$ \\
\hline & learning & $\begin{array}{l}\text { parents mention } \\
\text { learning, } \\
\text { development, growth }\end{array}$ & $\begin{array}{l}\text { Learning at the Centre - it gives a great } \\
\text { indication of the types of activities } \\
\text { undertaken and the learning aims eg. a } \\
\text { story on our child exploring the sandpit } \\
\text { and building up the courage to explore } \\
\text { further in different ways. A story about } \\
\text { our child using different vessels to pour } \\
\text { and measure water quantities and what } \\
\text { skills the teacher saw being used and }\end{array}$ \\
\hline
\end{tabular}




\begin{tabular}{|c|c|c|c|}
\hline & & & developed \\
\hline & $\begin{array}{l}\text { Learning at } \\
\text { home }\end{array}$ & $\begin{array}{l}\text { Taking what child is } \\
\text { doing at centre and } \\
\text { applying it at home }\end{array}$ & $\begin{array}{l}\text { So this way I can see what exactly is } \\
\text { being taught and am able to support this } \\
\text { learning at home. }\end{array}$ \\
\hline & relationships & $\begin{array}{l}\text { Parents mention } \\
\text { relationships with } \\
\text { teachers or children }\end{array}$ & $\begin{array}{l}\text { also the teachers put stories up of their } \\
\text { holidays, which I feel strengthens the } \\
\text { bond \& makes the centre \& teachers feel } \\
\text { more like family }\end{array}$ \\
\hline & $\begin{array}{l}\text { Face to face } \\
\text { conversations }\end{array}$ & $\begin{array}{l}\text { Parents mention face } \\
\text { to face conversations }\end{array}$ & $\begin{array}{l}\text { It's good to be able to see photos and videos } \\
\text { that reinforce conversations had with } \\
\text { teachers during pick-up or drop-offs }\end{array}$ \\
\hline $\begin{array}{l}\text { Reasons for } \\
\text { commenting or } \\
\text { adding a story }\end{array}$ & & $\begin{array}{l}\text { Parents describe why } \\
\text { they comment or add } \\
\text { stories of their own }\end{array}$ & $\begin{array}{l}\text { Being able to build rapport with the } \\
\text { teachers through comments. }\end{array}$ \\
\hline & Affirmation & $\begin{array}{l}\text { Descriptions include } \\
\text { being proud, excited, } \\
\text { celebratory, }\end{array}$ & $\begin{array}{l}\text { I try not to make general comments (ones } \\
\text { you would make on a facebook post) more } \\
\text { comments to celebrate his achievements }\end{array}$ \\
\hline & Appreciation & $\begin{array}{l}\text { To show appreciation } \\
\text { of the teachers } \\
\text { work/time. 'Thanking' } \\
\text { 'appreciation' } \\
\text { acknowledgment' } \\
\text { used }\end{array}$ & $\begin{array}{l}\text { and thanks for the teacher for sharing } \\
\text { the story }\end{array}$ \\
\hline & Learning & $\begin{array}{l}\text { To support ongoing } \\
\text { learning }\end{array}$ & $\begin{array}{l}\text { Exchange information with teacher, so } \\
\text { parents and teachers can work together } \\
\text { to nurture some particular interest or } \\
\text { encourage the child's learning and } \\
\text { development in a particular area/subject. }\end{array}$ \\
\hline & $\begin{array}{l}\text { Provide more } \\
\text { information }\end{array}$ & $\begin{array}{l}\text { Making links between } \\
\text { home and centre, } \\
\text { providing information }\end{array}$ & $\begin{array}{l}\text { Communication about home life - we } \\
\text { try to post regularly about our child's } \\
\text { home life and her interests eg, stories } \\
\text { about body painting at home, about }\end{array}$ \\
\hline
\end{tabular}




\begin{tabular}{|l|l|l|l|}
\hline & for teachers & feeding the cat etc. \\
\hline compunication & & $\begin{array}{l}\text { Types of } \\
\text { communication that } \\
\text { the ePortfolio has } \\
\text { inspired between } \\
\text { teachers and parents. } \\
\text { Parents talk about } \\
\text { communication } \\
\text { responses are positive and constructive }\end{array}$ & \\
& & $\begin{array}{l}\text { between home and } \\
\text { centre 'responding' } \\
\text { 'comments' 'reply } \\
\text { back' }\end{array}$ & \\
& & \\
\hline
\end{tabular}

